\title{
Evaluation of a Versatile Experimental Salt Irradiation Loop (VESIL) inside the Advanced Test Reactor
}

Abdalla Abou-Jaoude, Joe Palmer, James Sterbentz, and Pattrick Calderoni May 2019

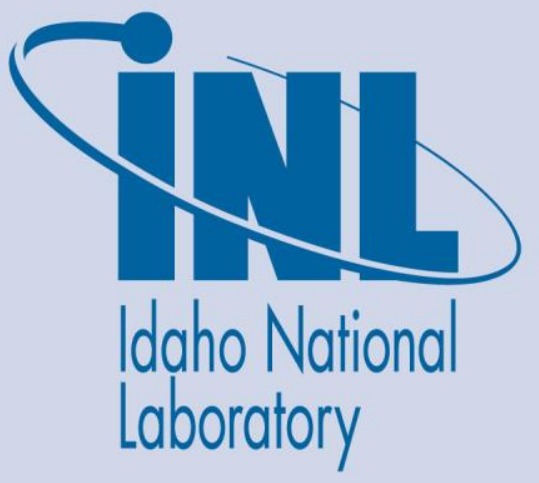

The INL is a U.S. Department of Energy National Laboratory operated by Battelle Energy Alliance 


\section{DISCLAIMER}

This information was prepared as an account of work sponsored by an agency of the U.S. Government. Neither the U.S. Government nor any agency thereof, nor any of their employees, makes any warranty, expressed or implied, or assumes any legal liability or responsibility for the accuracy, completeness, or usefulness, of any information, apparatus, product, or process disclosed, or represents that its use would not infringe privately owned rights. References herein to any specific commercial product, process, or service by trade name, trade mark, manufacturer, or otherwise, does not necessarily constitute or imply its endorsement, recommendation, or favoring by the U.S. Government or any agency thereof. The views and opinions of authors expressed herein do not necessarily state or reflect those of the U.S. Government or any agency thereof. 


\section{Evaluation of a Versatile Experimental Salt Irradiation Loop (VESIL) inside the Advanced Test Reactor}

Abdalla Abou-Jaoude, Joe Palmer, James Sterbentz, and Pattrick Calderoni

May 2019

Idaho National Laboratory Idaho Falls, Idaho 83415

http://www.inl.gov

Prepared for the

U.S. Department of Energy

Office of Nuclear Energy

Under DOE Idaho Operations Office

Contract DE-AC07-05ID14517 


\begin{abstract}
A Versatile Experimental Salt Irradiation Loop (VESIL) is under investigation at Idaho National Laboratory. An initial feasibility study was conducted for potential deployment inside the Advanced Test Reactor (ATR). Historical salt-irradiation tests are reviewed and summarized in this report. The study also surveys available instrumentation for this type of application and identifies key design and testing requirements. Neutronic analysis was performed in different ATR position for various salt candidates using MCNP6 and ORIGEN-6.2. The results indicate that both the B and I-positions are suitable for VESIL. The B-position allows for accelerated testing in light of its higher flux, but its smaller volume may be detrimental for a flowing loop. The O-position flux level was found to be insufficient for the purposes of this experiment; it is not recommended. In all the different salt candidates investigated, both the B and I-positions are found to able to reach adequate burnup conditions that are representative of the operating conditions inside proposed molten-salt reactor concepts.
\end{abstract}




\section{CONTENTS}

ABSTRACT .ii

ACRONYMS vii

1. INTRODUCTION AND BACKGROUND 1

1.1 Interest in Molten-Salt Reactor Concepts .......................................................................... 1

1.2 Historical Review of Salt-Irradiation Experiments ................................................................ 2

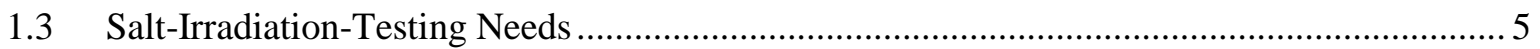

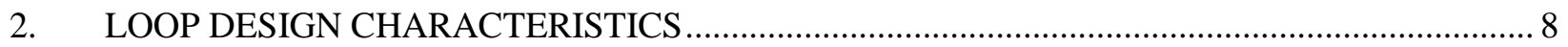

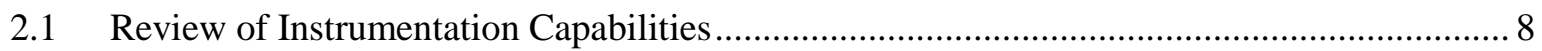

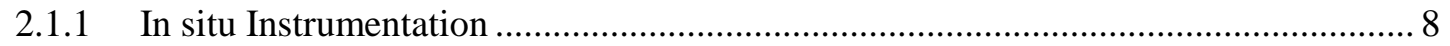

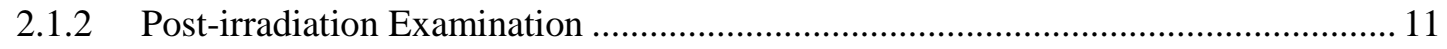

2.1.3 Chemistry Control and Component Demonstration................................................ 12

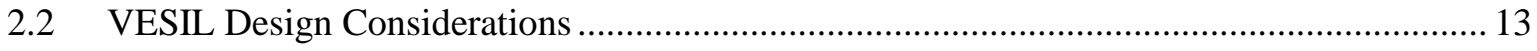

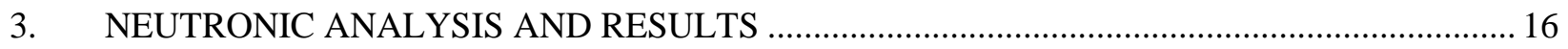

3.1 Modeling the Advanced Test Reactor.............................................................................. 16

3.2 Parametric Study of Salt Irradiation.......................................................................... 21

3.2.1 Summary of ORIGEN Depletion Results ........................................................... 22

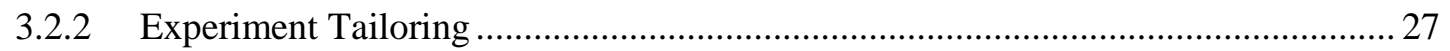

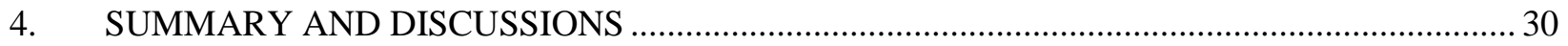

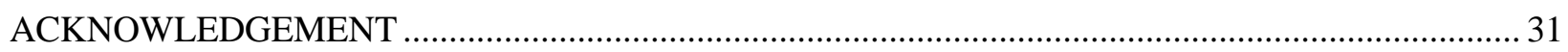

FIGURES

Figure 1. Diagram illustrating two of the design paradigms facing current MSR concepts.......................2

Figure 2. Diagram of the MTR circulating fused-salt irradiation test loop (taken from [4])...................... 3

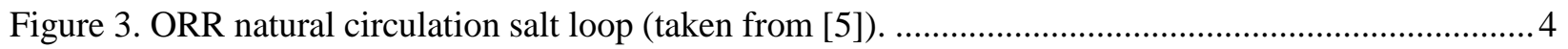

Figure 4. Diagram of the salt capsule irradiation at the MITR (taken from [8]). .................................... 4

Figure 5. Different testing stages for MSR research and development (R\&D) programs. This report focuses on phase IV.

Figure 6. Illustration of the gas flow monitoring system for the AGR-1 experiment. The capsuled labeled 1 to 5 contain fuel particles and are within the ATR core (taken from [17]). 10

Figure 7. Example of an external flow loop in the ATR (left, taken from [23]), and an internal cartridge-type loop used in BOR-60 (right, taken from [24]).

Figure 8. Illustration of the two different designs under consideration for VESIL. Design A relies on natural circulation for flow, while Design B uses a pump.

Figure 9. Diagram of the ATR core with the different experiment positions. The three positions used for the analysis in this report (B-11, I-11, and OS-5) are highlighted in red. (Taken from [27]) . 
Figure 11. Comparison of the normalized flux per unit lethargy in the B-position of the ATR. Data from the other two curves was provided from two experienced ATR analysts. Error bars are too small to appear in the plot. 20

Figure 12. Comparison of the normalized flux per unit lethargy in the I-position of the ATR.

Figure 13. Comparison of the MCNP6 tallied normalized spectrum in the B-, I-, and O-position. Error bars are too small to appear in the plot.

Figure 14. The evolution of ${ }^{235} \mathrm{U}$ fission energy with the salt enrichment in six ATR positions.

Figure 15. Evolution of tritium production per volume of irradiated FLiBe salt with lithium enrichment.

Figure 16. Impact of ${ }^{37} \mathrm{Cl}$ enrichment in REBUS salt on sulfur production from ${ }^{35} \mathrm{Cl}$ transmutation rate.

Figure 17. Evolution of the ${ }^{233} \mathrm{U}$ concentration inside the MSBR salt in the B and I-positions. The simulations assumed that all the salt is contained within the active flux region. 30

\section{TABLES}

Table 1. Overview of different MSR concepts and proposed fuel-bearing salts being developed across the world. 1

Table 2. Summary of in-pile salt-irradiation tests

Table 3. Irradiation-affected phenomena that are within the scope of VESIL. Category indexes are based on the previously provided list: (A) neutronics, (B) salt properties,

(C) fission-product transport, (D) corrosion effects, and (E) operational validation. .8

Table 4. Summary of possible VESIL instrumentation for in situ measurements. The item numbers in the second column correspond to the identified phenomena testing objectives in Table 3.

Table 5. List of potential PIE measurements for VESIL. The item numbers in the second column correspond to the identified phenomena testing objectives in Table 3.

Table 6. Processing and removal rates for different fission products in the MSBR (taken from Table 2 of ORNL-TM-3579 [19]).

Table 7. Summary of the two design options for VESIL. The phenomena numbers correspond to those listed in Table 3.

Table 8. ATR operating characteristics used in the analysis. Based on values from [27] ....................... 17

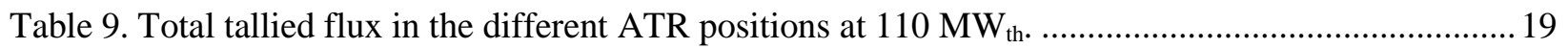

Table 10. Candidate salts considered in the parametric study.

Table 11. Production rates per unit of irradiated salt volume $\left(\mathrm{cm}^{3}\right)$ in the $\mathrm{B}, \mathrm{I}$ and $\mathrm{O}$-positions of the ATR, after one cycle. Concentrations lower than $10^{-6} \mathrm{~g} / \mathrm{cm}^{3}$ are cutoff from the results.

Table 12. Parametric evaluation per unit of irradiated salt volume $\left(\mathrm{cm}^{3}\right)$ in the $\mathrm{B}$, I, and $\mathrm{O}$ positions of the ATR. Very low values are not reported. 
Table 13. Total quantity of element produced after 1 ATR cycle, assuming that the salt occupies $30 \%$ of the available experiment-position volume. Activity and decay heat values are at EOC.

Table 14. Density (in $\mathrm{g} / \mathrm{cm}^{3}$-salt) of isotopes/elements after 1 cycle irradiation in the ATR (60 days)...... 


\section{ACRONYMS}

AGR Advanced Gas Reactor (experiment)

ARE Aircraft Reactor Experiment

ATR Advanced Test Reactor

DOE-NEET Department of Energy, Nuclear Energy Enabling Technologies

EFPD effective full-power day

HFR High Flux Reactor

IET Integral Effects Test

INL Idaho National Laboratory

LITR Low Intensity Test Reactor

MITR MIT Reactor

MSR molten-salt reactors

MSRE Molten Sat Reactor Experiment

MTR Materials Test Reactor

NRC Nuclear Regulatory Commission

ORNL Oak Ridge National Laboratory

ORR Oak Ridge Research Reactor

OSURR Ohio State University Research Reactor

PIE post-irradiation examination

PWR pressurized water reactors

R\&D research and development

VESIL Versatile Experimental Salt Irradiation Loop

TRISO tri-structural isotopic 


\section{Evaluation of a Versatile Experimental Salt Irradiation Loop (VESIL) inside the Advanced Test Reactor}

\section{INTRODUCTION AND BACKGROUND}

\subsection{Interest in Molten-Salt Reactor Concepts}

Molten-salt reactors (MSRs) have been gaining interest and support, both at the commercial and the governmental level. While MSR technology was demonstrated in the 1960s [1], only a narrow range of salt compositions and structural materials have been evaluated. Many of the proposed MSR concepts summarized in Table 1 rely on relatively untested salts (notably chloride-based salts). In all likelihood, many of these proposed salts will need to be evaluated under neutron irradiation conditions before approved by the Nuclear Regulatory Commission (NRC).

Table 1. Overview of different MSR concepts and proposed fuel-bearing salts being developed across the world.

\begin{tabular}{|c|c|c|c|c|c|c|c|}
\hline Company & Concept & Spectrum & $\begin{array}{l}\text { Fuel } \\
\text { Type }\end{array}$ & $\begin{array}{l}\text { Fuel } \\
\text { Cycle }\end{array}$ & $\begin{array}{l}\text { Power } \\
\left(\text { MW }_{\text {th }}\right)\end{array}$ & Fuel/Coolant & Country \\
\hline ThorCon & TC Can & Thermal & Liquid & Th-U & 557 & $\mathrm{NaF}+\mathrm{BeF}_{2}+\mathrm{ThF}_{4}+\mathrm{UF}_{4}$ & USA \\
\hline Seaborg & CUBE & Thermal & Liquid & Th-U & 50 & $\mathrm{LiF}+\mathrm{Th} / \mathrm{U} / \mathrm{MA}-\mathrm{F}_{\mathrm{x}}$ & Denmark \\
\hline Flibe & LFTR & Thermal & Liquid & Th-U & 600 & $\mathrm{LiF}+\mathrm{BeF}_{2}+\mathrm{ThF}_{4}+\mathrm{UF}_{4}$ & USA \\
\hline AlphaTech & N/A & Thermal & Liquid & Th-U & $\mathrm{N} / \mathrm{A}$ & $\mathrm{LiF}+\mathrm{BeF}_{2}+\mathrm{ThF}_{4}+\mathrm{UF}_{4}$ & USA \\
\hline TUT & FUJI & Thermal & Liquid & Th-U & 450 & $\mathrm{LiF}+\mathrm{BeF}_{2}+\mathrm{ThF}_{4}+\mathrm{UF}_{4}$ & Japan \\
\hline SINAP & TMSR-LF & Thermal & Liquid & Th-U & 2 & $\mathrm{LiF}+\mathrm{BeF}_{2}+\mathrm{ThF}_{4}+\mathrm{UF}_{4}$ & China \\
\hline Terrestrial & IMSR & Thermal & Liquid & $\mathrm{U}-\mathrm{Pu}$ & 400 & $\mathrm{UF}_{4}$ no $\mathrm{Be}$ or $\mathrm{Li}$ & Canada/US \\
\hline Transatomic & TAP & Epithermal & Liquid & $\mathrm{U}-\mathrm{Pu}$ & 520 & $\mathrm{LiF}+\mathrm{UF}_{4}$ & USA \\
\hline Moltex & SSR & Ther/Fast & Liquid & $\mathrm{U} / \mathrm{Th}$ & 150 & $\mathrm{NaCl}+\mathrm{UCl}_{3}$ & UK \\
\hline Elysium & MCSFR & Fast & Liquid & $\mathrm{U}-\mathrm{Pu}$ & 2,500 & $\mathrm{NaCl}+\mathrm{UCl}_{3}$ & USA \\
\hline Terrapower & MCFR & Fast & Liquid & $\mathrm{U}-\mathrm{Pu}$ & 1,100 & $\mathrm{NaCl}+\mathrm{UCl}_{3}$ & USA \\
\hline PSI & SOFT & Fast & Liquid & $\mathrm{U}-\mathrm{Pu}$ & 2,000 & $\mathrm{NaCl}+\mathrm{UCl}_{3}$ & Switzerland \\
\hline SAMOFAR & MSFR & Fast & Liquid & Th-U & 3,000 & $\mathrm{LiF}+\mathrm{ThF}_{4}+\mathrm{UF}_{4}$ & $\mathrm{EU}$ \\
\hline Kurchatov & MOSART & Fast & Liquid & Th-U & 2,400 & $\mathrm{LiF}+\mathrm{BeF}_{2}+\mathrm{ThF}_{4}+\mathrm{UF}_{4}$ & Russia \\
\hline SINAP & TMSR-SF & Thermal & Solid & $\mathrm{U}-\mathrm{Pu}$ & 10 & TRISO $^{\mathrm{a}} \& \mathrm{LiF}+\mathrm{BeF}_{2}$ & China \\
\hline Kairos & PB-FHR & Thermal & Solid & $\mathrm{U}-\mathrm{Pu}$ & N/A & TRISO \& $\mathrm{LiF}+\mathrm{BeF}_{2}$ & USA \\
\hline ORNL & FHR-D & Thermal & Solid & $\mathrm{U}-\mathrm{Pu}$ & 100 & TRISO \& $\mathrm{LiF}+\mathrm{BeF}_{2}$ & USA \\
\hline Yellowstone & N/A & Thermal & Solid & $\mathrm{U}-\mathrm{Pu}$ & 500 & $\mathrm{UO}_{2} \&$ Nitrate salt & USA \\
\hline
\end{tabular}

a tri-structural isotropic coated fuel pellets

MSR concepts tend to have four defining characteristics: (1) neutron spectra: thermal or fast, (2) fuel type: solid or liquid, (3) fuel cycle: U-Pu or Th-U, and (4) salt solution type: fluoride, chloride, or nitrate. Figure 1 illustrates the variability between neutron spectrum and fuel cycle. Of the companies illustrated, only Kairos and YellowStone Energy employ a solid fuel (TRISO and $\mathrm{UO}_{2}$ respectively), and Moltex uses a static liquid fuel, as summarized in Table 1. There is a need for irradiating both so-called fueled and unfueled (i.e., "clean") salt. Each design promises advantages over conventional pressurized water 
reactors (PWRs). Dissolving salt in a liquid allows for theoretically unlimited burnup and opens the possibility of closing the fuel cycle without sensitive chemical processing. These reactors have enhanced safety by virtue of very strong negative-feedback coefficients and the continuous removal of some fission products (notably the volatile and semi-volatile elements). These reactors avoid the challenges of structural fuel-element fabrication and promise a simpler core design that can operate at high power density and with high thermal efficiency. Designs with solid fuels (e.g. Kairos) highlight the safety benefits of uranium-encapsulated TRISO particles and the capability of online refueling. Other companies such as Yellowstone emphasize the ability to leverage the existing fuel-cycle infrastructure for their use of commercial $\mathrm{UO}_{2}$ fuel. As a result of all these differences, each concept is anticipated to have varying testing requirements; consequently, this highlights the need for a Versatile Experimental Salt Irradiation Loop (VESIL) that would be deployed inside the Advanced Test Reactor (ATR) at Idaho National Laboratory (INL).

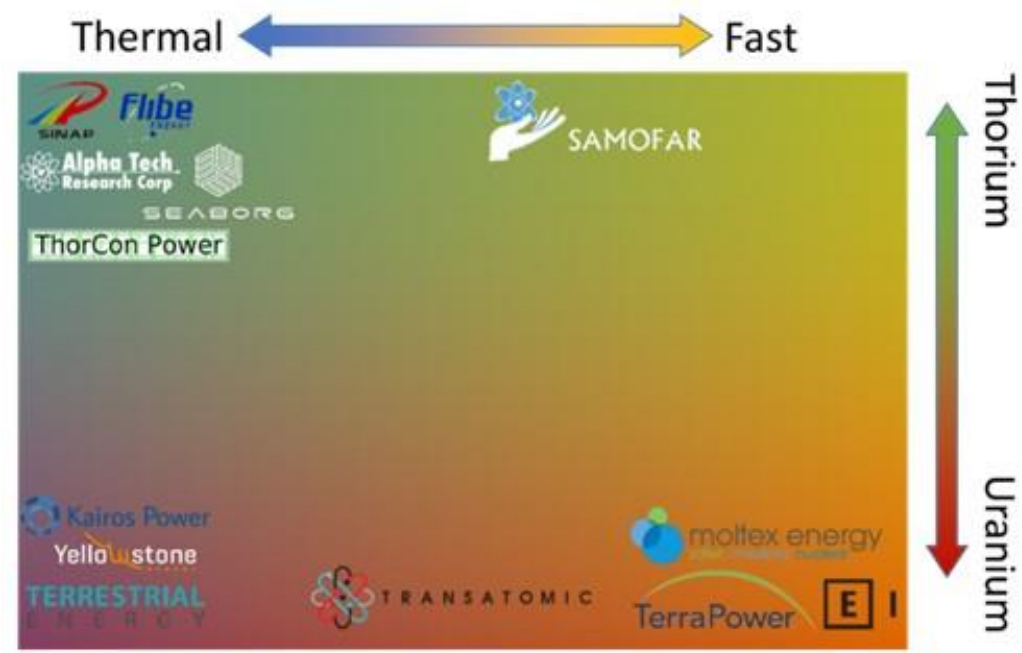

Figure 1. Diagram illustrating two of the design paradigms facing current MSR concepts.

\subsection{Historical Review of Salt-Irradiation Experiments}

Oak Ridge National Laboratory recently published a report summarizing some of the previous in-pile testing facilities developed for molten salts [2]. Very limited irradiation data exists for most of the MSR concepts highlighted in Table 1, notably chloride-based fast systems. The vast majority of experience stems from two major programs: The Aircraft Reactor Experiment (ARE) [3], and the Molten Salt Reactor Experiment (MSRE) [1]. The salts considered in both instances were fluoride-based $\left(\mathrm{NaF}_{-} \mathrm{ZrF}_{4}-\right.$ $\mathrm{UF}_{4}$ and $\mathrm{LiF}-\mathrm{BeF}_{2}-\mathrm{ZrF}_{4}-\mathrm{UF}_{4}$, respectively). The ARE operated for several weeks during 1954 , and the MSRE, from 1965 to 1969. These experiments demonstrated a wide variety of operating features of MSR concepts, most notably the stability of the salt under irradiation conditions, continuous salt-chemistry processing and control, and reliability of system components (e.g., pumps and valves).

Even more relevant for the purposes of this report are smaller in-pile irradiation experiments that helped support the two programs. The tests were conducted at three reactor facilities: (1) the Materials Test Reactor (MTR) [4], (2) the Low Intensity Test Reactor (LITR) [3], and (3) the Oak Ridge Research Reactor (ORR) [5]. These experiments were all operated between 1950 and 1970. The MTR experiments considered different fuel-bearing fluoride salts. Their main interest was metal corrosion under irradiation. The maximum temperature and total flux were $870^{\circ} \mathrm{C}$ and $6 \times 10^{13} \mathrm{n} / \mathrm{cm}^{2}$-s [4]. The LITR experiments consisted of dynamic tests for the ARE, including tube-burst experiments at $800^{\circ} \mathrm{C}$ and pumpperformance demonstrations [3]. The experiments deployed in ORR were natural circulation-driven with an objective to study the compatibility of fuel salt with graphite and Hastelloy N [5]. 
Of the various experiments conducted, the most relevant to VESIL is the fused-salt loop deployed in the MTR, shown in Figure 2. The self-contained, cartridge-type experiment was compact and versatile. Different loop designs were tested (around eight iterations), and different pump designs were developed and implemented. The maximum fission power density reached within the loop was $250 \mathrm{~W} / \mathrm{cm}^{3}$. The experiment faced numerous challenges, notably relating to electrical and thermocouple failure, plugging of purging systems, salt leakages, unstable pump speeds, and coolant-temperature control [6]. These will all need careful attention for the design of VESIL. Additional lessons learned from the MTR experiment include "the complexity of the installation necessitat[ing] full time operator coverage," with "operational difficulties hav[ing] largely resulted from crowding of equipment." [4] Modifications to the original design will attempt to further simplify the system. For instance, cooling of the loop was achieved by continuously pumping air from outside the reactor vessel. The added complexity of such a system can be avoided with VESIL by relying on a thermal interface with the ATR coolant.

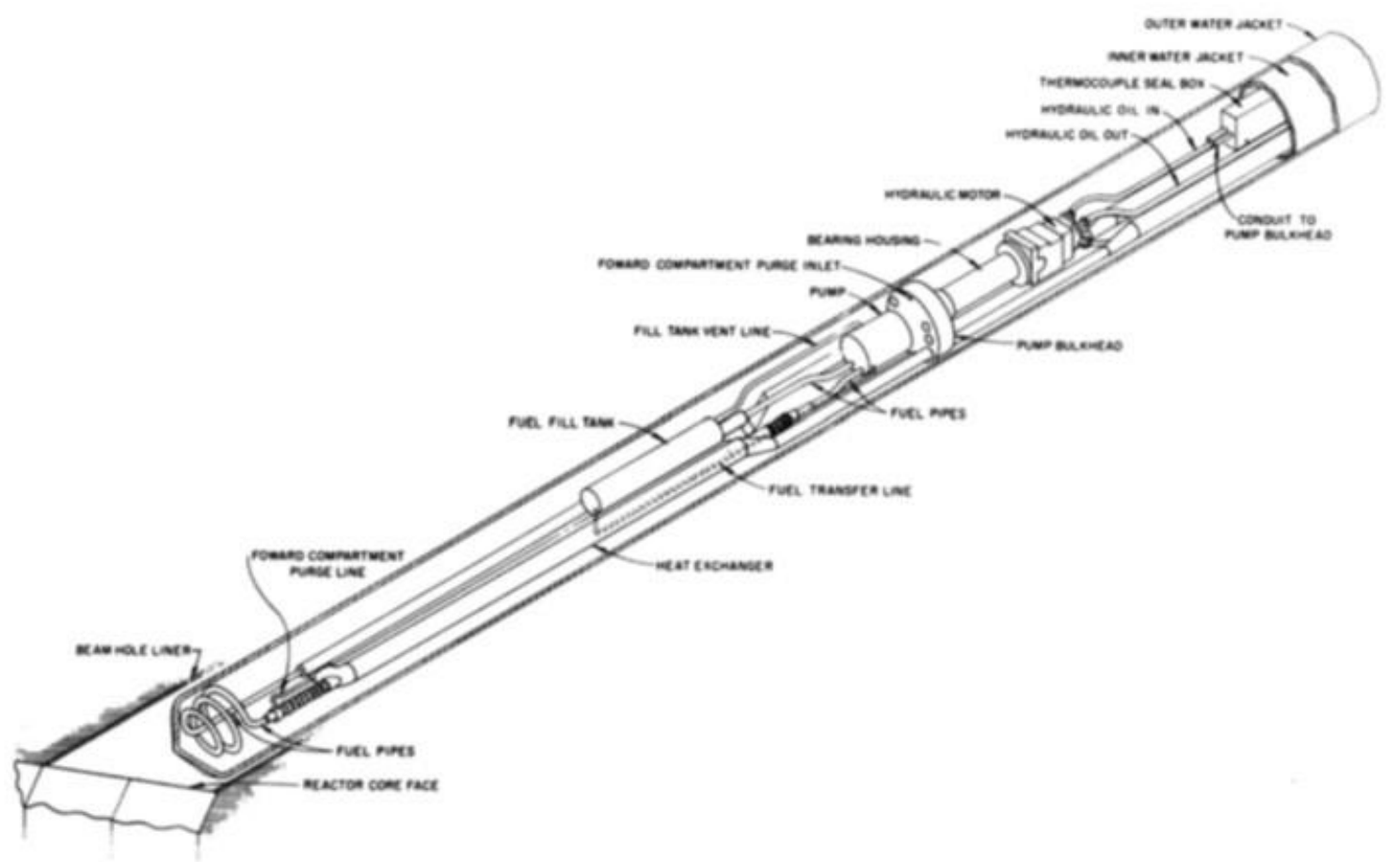

Figure 2. Diagram of the MTR circulating fused-salt irradiation test loop (taken from [4]).

Less information is available on the oldest experiment (at LITR). The vertical loop inside the reactor was mainly for transient analyses and pump-performance demonstration. One of the main concerns during operation was condensation of fluoride compounds (notably $\mathrm{ZrF}_{4}$ ) [3]. These types of issues must be anticipated in VESIL as well. While the other two reactor experiments were self-contained within positions inside the core, the ORR experiments were larger and positioned at the vicinity of the core, inside beam holes. Figure 3 shows an illustration of the loop. A total of 3,439 hours of irradiated operation were accrued. Two iterations of the loop were constructed, and both were dismantled following breaks in the primary loop system. The maximum power density reached in the system was $165 \mathrm{~W} / \mathrm{cm}^{3}$. A combination of 21 resistive heaters and four air coolers controlled the salt temperature. The main challenge faced with the operation of the ORR experiment related to leakages at component interfaces (e.g., at the cooler and salt injection system) [5]. 


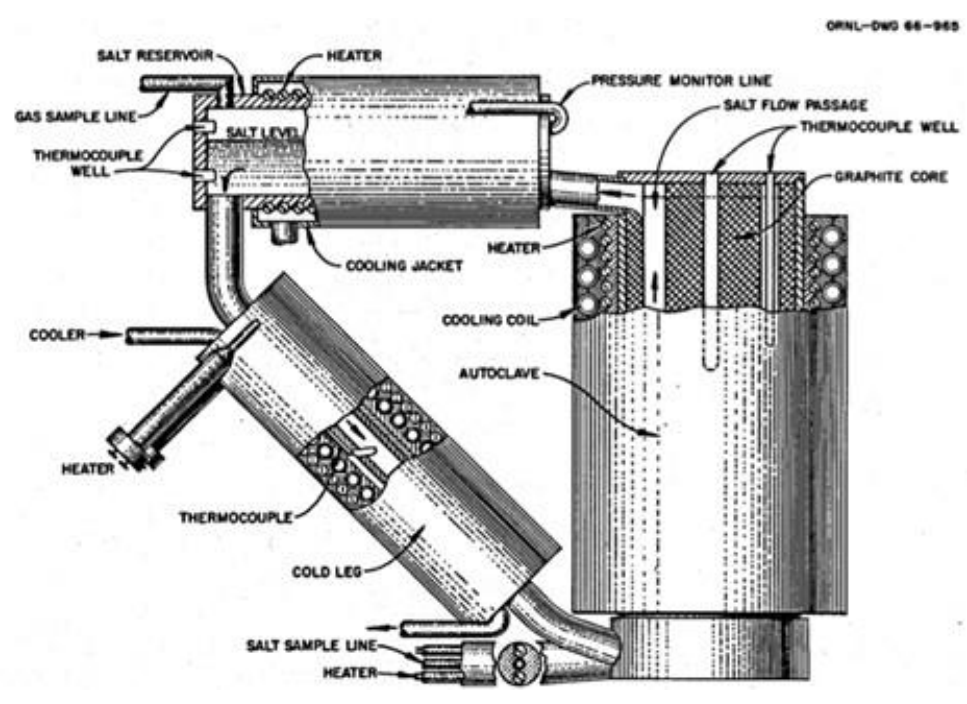

Figure 3. ORR natural circulation salt loop (taken from [5]).

More recently and with renewed interest in MSRs, fueled-salt irradiation experiments were conducted at the Petten High Flux Reactor (HFR) [7], together with non-fueled ones at the MIT Reactor (MITR) [8], at LR-0 in Rez [9], and at the Ohio State University Research Reactor (OSURR) [10]. All of these tests were static experiments. Figure 4 illustrates a sample diagram of the layout of one such an experiment at the MITR. Most of the experiments keep the salt contained within electrically heated graphite crucibles, with additional steel containment to monitor for leakage.

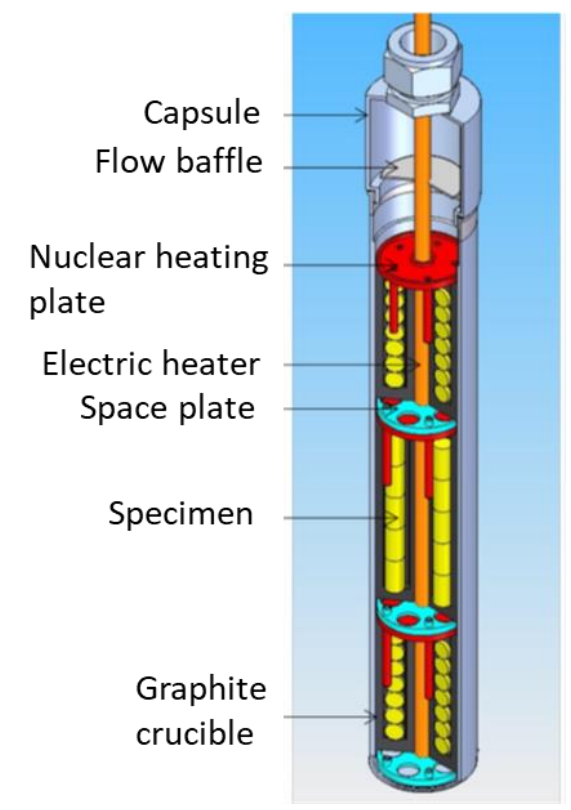

Figure 4. Diagram of the salt capsule irradiation at the MITR (taken from [8]).

The HFR test contained thorium; its objective was to confirm basic fission-product-related behavior in MSR systems. Salt capsules were successfully irradiated for nine operating cycles and are currently undergoing post-irradiation examination (PIE). Future iterations of the experiment intend to investigate fission-product effects on Hastelloy $\mathrm{N}$ more closely and to monitor fission-gas release. The new iterations would be fitted with heaters to avoid radiolysis during reactor downtime and rely on additional instrumentation for pressure and temperature monitoring [7]. The LR-0 experiment was used to validate cross-sections associated with a solid-fuel, fluoride-cooled reactor system. Results from the sensitivity 
analysis determined that ${ }^{7} \mathrm{Li}$ capture contributes to the largest source of eigenvalue uncertainty [9]. The MITR experiment was mainly intended for tritium production and capture and corrosion studies. It replicated conditions in an out-of-pile experiment to compare corrosion rates in various filters (graphite, carbon fiber, SS316, Hastelloy, SiC, etc.). Tritium release was measured both in situ and during PIE. Different graphite samples were tested to evaluate their ability to act as a capture medium for the gas [8]. Last, the OSURR experiment was designed to provide some initial data on chloride-salts irradiation. The main objective was to evaluate the effect of neutron bombardment and radiolysis on corrosion rates [10].

A summary of the different salt-irradiation experiments conducted is provided in Table 2 . While a wide range of experiments were conducted, a relatively narrow range of salts (mostly FLiBe-based) and structural material were considered. In addition, none of the more recent experiments attempted to circulate the fuel salt, relying instead on static capsule irradiation. This highlights the need for a new, versatile test facility that can support various MSR concepts currently under development. Insights from the different experiments will inform the design of VESIL.

Table 2. Summary of in-pile salt-irradiation tests.

\begin{tabular}{|c|c|c|c|c|c|}
\hline Reactor & Salt Type & Structure & Year & $\mathbf{T}_{\max }$ & Circulation \\
\hline LITR & $\mathrm{NaF}-\mathrm{ZrF}_{4}-\mathrm{UF}_{4}$ & Inconel & 1956 & $870^{\circ} \mathrm{C}$ & forced \\
\hline MTR & $\mathrm{NaF}-\mathrm{ZrF} \mathrm{F}_{4}-\mathrm{UF}_{4}$ & Inconel + Hastelloy $\mathrm{N}$ & 1958 & $870^{\circ} \mathrm{C}$ & forced \\
\hline ORR & 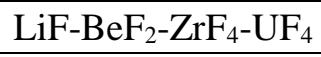 & Hastelloy N & 1966 & $650^{\circ} \mathrm{C}$ & natural \\
\hline LR-0 & $\mathrm{LiF}_{-\mathrm{BeF}_{2}}$ & Graphite & 2017 & $700^{\circ} \mathrm{C}$ & static \\
\hline MITR & $\mathrm{LiF}_{-\mathrm{BeF}}$ & Graphite & 2017 & $700^{\circ} \mathrm{C}$ & static \\
\hline OSURR & $\mathrm{KCl}-\mathrm{MgCl}$ & Molybdenum alloy & 2018 & $800^{\circ} \mathrm{C}$ & static \\
\hline HFR & $\mathrm{LiF}_{-\mathrm{ThF}}$ & Graphite & 2018 & $600^{\circ} \mathrm{C}$ & static \\
\hline
\end{tabular}

\subsection{Salt-Irradiation-Testing Needs}

All MSR concepts will require a dedicated testing campaign to reach commercialization. The NRC defines two different types of experiments: those analyzing separate effects and those measuring integrated ones. As defined by NUREG-0800 Chapter 15.0.2 [11]:

Separate Effects Test (SET): An experiment in which the primary focus is on a single parameter or process. [...] Separate effects testing must be performed to demonstrate the adequacy of the physical models to predict physical phenomena that were determined to be important by the accident scenario identification process. Separate effects testing must also be used to determine the uncertainty bounds of individual physical models.

In the case of an MSR design, a SET can include the measurement of specific salt properties such as viscosity. On the other hand, an integrated effect test, as defined below, would deal with aspects of the reactor such as enhanced corrosion rates due to accumulation of fission products in the salt.

Integral Effects Test (IET): An experiment in which the primary focus is on the interactions between parameters and processes. [...] Integral effects testing must be performed to demonstrate that the interactions between different physical phenomena and reactor coolant system components and subsystems are identified and predicted correctly.

A proposed molten-salt irradiation-testing experiment will need to clearly outline its corresponding SETs and IETs. A wide range of irradiation-driven phenomena require experimental data validation. They are grouped into five general categories and summarized below. The list is not expected to be comprehensive, but mainly intends to highlight the wide range of different testing needs envisaged for a potential experiment. 
A. Neutronic characteristics

- $\quad$ Nuclear data and integral cross-section measurements (notably as relating to ${ }^{35} \mathrm{Cl}$ )

- Delayed neutron precursor drift (cause by delayed neutrons being emitted outside the core region, lowering the $\beta_{\text {eff }}$ value)

- Quantification and validation of reactivity feedback coefficients

- Validation of neutronic, depletion, and coupled codes (e.g., fission rate, temperature predictions)

B. Salt and solute property evolution under irradiation

- Thermophysical properties (e.g., density, viscosity, heat capacity)

- Establishing radiation stability of salt and assessing formation of exotic salt compounds (e.g., $\mathrm{UCl}_{6}, \mathrm{CsF}_{2}$ ) as well as free radicals and redox potential (e.g., $\mathrm{U}^{4+} / \mathrm{U}^{3+}$ ratio)

C. Fission-product mass transport accountancy

- $\quad$ Production and behavior of activation products (e.g., ${ }^{3} \mathrm{H}, \mathrm{P}, \mathrm{S}$ )

- Solubility and diffusion rates of different fission products in salt (notably Xe)

- Source term data (including volatilization of I and Cs compounds under different conditions)

- Precipitation and plating of noble metals, actinides, and other salt compounds

- Validation of species transport codes

D. Irradiation enhanced corrosion effects

- Impact of radiolysis and fission-product impurities (notably Te)

- $\quad$ Structural material post-irradiation evaluation (PIE)

- Evaluation of samples and coupons inside flow area

E. Operational validation

- Demonstrate operations for given conditions $\left({ }^{\circ} \mathrm{C}, \mathrm{m} / \mathrm{s}, \mathrm{Re}\right.$ no., $\mathrm{W} / \mathrm{cm}^{3}$, concentration etc.)

- Component testing (e.g., seals and pumps)

- Remote redox chemistry control proof-of-concept (e.g., electrolysis of U/Be, purification system)

A wide range of experiments can be envisioned to account for these different phenomena, as illustrated in Figure 5. They are ranked in order of difficulty, with VESIL fitting under Category IV. Outof-pile experiments employing surrogate material would be the easiest to conduct as an initial phase. Companies such as Terrapower are conducting numerous tests in this category [12]. The next simplest is testing and measurement inside a critical pile or a "zero-power" reactor facility (e.g., LR-0 [9]).

Criticality experiments can shed light on important neutronic behavior of the salt. The third stage is static salt-irradiation capsules; these are being undertaken at HFR [7], MITR [8], and OSR [10]. This

effectively constitutes a SET, providing some initial data on the salt/structure behavior in a neutron field. The fourth category - and the topic of this report - consists of a circulating in-pile loop to measure the integrated effect of flow with irradiation. Last, a demonstration plant will be necessary for most, if not all concepts before commercial deployment. Because the VESIL experiment encompasses solely the fourth category, care must be taken to ensure its test objectives do not overlap with those of different categories. 


\section{Out of pile loop}

- Unirradiated salt/solute properties

- Materials compatibility (corrosion)

\section{Critical Pile Test}

- Nuclear data measurement

- Delayed neutron precursor drift evaluation

\section{Static salt irradiation}

- Generation of activation products

- Limited fission product behavior

\section{Circulating in-pile loop}

- Representative salt properties and mass transport under irradiation

-Validation of salt chemistry control process ( ${ }^{3} \mathrm{~T}$, FPs etc.)

\section{Demonstration plant}

- Core-wide proof of concept

Figure 5. Different testing stages for MSR research and development (R\&D) programs. This report focuses on phase IV.

A review of MSR-related irradiation phenomena was conducted at INL. A relatively exhaustive list was generated, and items were binned under the different categories of Figure 5. The main phenomena that were allocated to VESIL are summarized in Table 3. They cover items from most of the five previously identified main categories, with the exception of neutronic characteristics. These phenomena are better suited for a critical pile test than a flowing salt loop inside a high-flux reactor. While certain aspects from the list (e.g., corrosion and thermophysical properties) could be tested in a static experiment, a circulating in-pile experiment is necessary to account for integrated effects. For instance, the combination of high fission-product concentration and high velocity can exacerbate corrosion effects. Lastly, VESIL is also intended to be leveraged as a proof-of-concepts for many components that would need to be deployed in a demonstration plant. This includes resistors for managing salt thawing, filters for fission-product polishing, redox control systems, heat exchangers, pump, valves, monitoring instrumentation, and many others. 
Table 3. Irradiation-affected phenomena that are within the scope of VESIL. Category indexes are based on the previously provided list: (A) neutronics, (B) salt properties, (C) fission-product transport, (D) corrosion effects, and (E) operational validation.

\begin{tabular}{|l|l|}
\hline Identified Phenomena & Category \\
\hline 1. Evolution of thermophysical properties with burnup and flow velocity & (B) \\
\hline 2. Variations in binary/ternary phase diagrams & (B) \\
\hline 3. Fission-product source term and transport out of the salt & (A) \& (C) \\
\hline 4. Material corrosion at high burnup and flow velocity & (D) \\
\hline 5. Precipitate formation and plate out of fission products and actinides & (C) \\
\hline 6. Volatilization of salt compounds including fission gases & (B) \& (C) \\
\hline 7. Demonstration of salt processing and fission-product polishing & (C) \& (E) \\
\hline 8. Management of localized salt freezing/thawing & (E) \\
\hline 9. Evolution of overall heat-transfer with burnup & (B) \& (E) \\
\hline 10. Component demonstration (e.g., resistors, valves, pumps) & (E) \\
\hline 11. Chemistry-control demonstration & (E) \\
\hline
\end{tabular}

\section{LOOP DESIGN CHARACTERISTICS}

\subsection{Review of Instrumentation Capabilities}

Obtaining useful information on the 11 identified items in Table 3 will require adequate instrumentation capabilities. A recent ORNL report (ORNL/TM-2018/868) provides a detailed overview of MSR measurement needs and requirements [13]. The report delves into details about the current status of salt instrumentation and provides an overview of areas in need of future research. This section builds on the ORNL report and focuses on the narrow needs of a circulating salt loop to address the phenomena listed in Table 3. Measurements can be grouped into two distinct categories: (1) live, in situ measurements inside the ATR, and (2) PIE that is conducted in dedicated hot-cell facilities. Chemistrycontrol systems are discussed in this section as well.

\subsubsection{In situ Instrumentation}

In situ measurement tools will have a direct impact on the design of VESIL. Measurement is particularly challenging in light of the harsh experiment environment. Instruments will need to be resistant to neutron/gamma bombardment, able to maintain accuracy under flowing conditions, and to survive the salt-chemistry environment. While it is preferable to transfer most of the testing to PIE, some listed phenomena must be measured in situ. This includes phenomena of very short timescales that can only be observed while fission reactions are occurring (e.g., volatile gas impact on bulk salt properties), as well as phenomena that are very sensitive to the salt handling and phase change after irradiation (e.g., fission-product solubility in salt). The different types of instruments that will need to be considered for VESIL are summarized in Table 4. They are not all anticipated to be deployed, but provide an initial starting point for loop design. 
Table 4. Summary of possible VESIL instrumentation for in situ measurements. The item numbers in the second column correspond to the identified phenomena testing objectives in Table 3.

\begin{tabular}{|c|c|c|c|}
\hline Instrument & Measurement & ATR Precedence & $\begin{array}{l}\text { R\&D } \\
\text { needs }\end{array}$ \\
\hline Thermocouples & $\begin{array}{l}\text { Salt freezing/thawing (\#8) } \\
\text { Evolution of thermal properties (\#1) } \\
\text { Heat-transfer correlations (\#9) }\end{array}$ & Yes & Low \\
\hline $\begin{array}{l}\text { Thermal needle } \\
\text { probes }\end{array}$ & Evolution of salt thermal conductivity (\#1) & Limited (static) & Medium \\
\hline $\begin{array}{l}\text { Frequency-based } \\
\text { conductivity }\end{array}$ & Evolution of salt thermal conductivity (\#1) & None & Medium \\
\hline $\begin{array}{l}\text { Calorimetric } \\
\text { cells }\end{array}$ & Evolution of salt melting point (\#1) & Limited & Medium \\
\hline Pressure gauge & Evolution of hydraulic properties (\#1) & Yes & Low \\
\hline $\begin{array}{l}\text { Flowmeter/ } \\
\text { Velocimeter }\end{array}$ & Evolution of hydraulic properties (\#1) & Very limited & Medium \\
\hline $\begin{array}{l}\text { Electro- } \\
\text { chemistry }\end{array}$ & $\begin{array}{l}\text { Changes in salt phase diagram (\#2) } \\
\text { Precipitation and plating effects (\#5) }\end{array}$ & Limited (static) & Low \\
\hline $\mathrm{pH}$ meter & Salt acidity and chemical composition (\#2) & Limited (static) & Medium \\
\hline $\begin{array}{l}\text { Fiber-optic } \\
\text { spectrometer }\end{array}$ & $\begin{array}{l}\text { Thermal properties evolution }(\# 1) \\
\text { Solubility of different elements in salt }(\# 2)\end{array}$ & $\begin{array}{l}\text { None (under } \\
\text { development) }\end{array}$ & High \\
\hline $\begin{array}{l}\text { Structural } \\
\text { distortions }\end{array}$ & $\begin{array}{l}\text { Crack growth and corrosion issues (\#4) } \\
\text { Thermal expansion and deformation (\#4) }\end{array}$ & Limited (dry) & Medium \\
\hline Off-gas system & $\begin{array}{l}\text { Tracking volatile gas activity (\#6) } \\
\text { Monitoring of gaseous source term (\#3) }\end{array}$ & $\begin{array}{l}\text { Limited } \\
\text { (e.g., Advanced } \\
\text { Gas Reactor*) }\end{array}$ & Medium \\
\hline $\begin{array}{l}\text { Salt-sampling } \\
\text { mechanism }\end{array}$ & $\begin{array}{l}\text { Freeze salt samples at specific intervals for } \\
\text { later PIE studies }(\# 1, \# 2)\end{array}$ & None & Medium \\
\hline
\end{tabular}

* A series of experiments conducted at ATR for TRISO fuel qualification

The first type of measurements needed for an experiment like VESIL are of the thermal variety. Thermocouples must be placed in a distributed fashion along the loop in order to monitor salt behavior and assess localized freezing and thawing during experiment startup and shutdown. They could also be leveraged to provide validation data for heat-transfer correlations. Ultrasound thermometers could also be used as an alternative to typical thermocouples. Thermal needle probes can be employed to measured thermal-conductivity evolution, but may be unable to provide reliable date under flowing conditions (VESIL may need to operate under different modes). Alternatively, more-advanced techniques, such as frequency-based conductivity analysis (similar to the 3-omega probe method) can be leveraged, but will require a substantial amount of $R \& D$ with out-of-pile validation. Calorimetric cells can be designed for in-pile measurements in static configurations, but will be difficult to leverage in a flowing environment. Accurate measurement will rely on the isolation of different parasitic effects (such as radiant-heat dissipation and heat dissipation through convection) and will be challenging to deploy for the purpose of VESIL.

The second type of instrumentation encompasses the hydraulic variety, notably flow meters and pressure gauges. These types of sensors will be employed to monitor the experiment, ensure adequate flow velocities are being measured, and measure the evolution of specific properties. The instruments can 
be setup to yield valuable information on the changes of salt properties with burnup (notably viscosity) by detecting variations in the flow meter or pump torque. These parameters would only be derived indirectly; they cannot be directly measured under flowing conditions. While pressure gauges have seen wide usage for in-pile instrumentations, velocimeters are less established, especially under a corrosive-salt environment. They would need a dedicated R\&D program before being deployed.

Evaluating salt-chemistry effects like constituent separation or diffusion of different species must also be measured in-pile. Electrochemical methods can be designed to specifically investigate complex transport properties in salts, but will require $R \& D$ and out-of-pile validations. These types of tools can additionally provide insight on plating effects. Fiber-optic-based spectroscopy can be used to monitor salt speciation and overall distribution of fission products. The applicability of fiber-based sensors to monitor irradiation test in material test reactors is being investigated as part of the Department of Energy, Nuclear Energy Enabling Technologies (DOE-NEET) program advanced instrumentation and sensor (ASI) research activities $[14,15]$.

Sensors could also be employed to measure structural distortions within the loop structural material. This could shed light on some corrosion effects and crack-propagation phenomena. They could prove useful to also study material properties of the loop structural material not included in Table 3 , such as creep rate (this could be addressed in out-of-pile experiments however). While these types of measurements have been conducted in the past, the experiments were only under dry conditions [16]. The electric potential of the salt renders measurement more difficult than what was previous considered.

The last type of in-situ measurement systems encompasses the sampling variety. An off-gas system would provide continuous insight on the salt burnup state, as well as direct access to data on the volatile gas species being formed in the salt. This includes insoluble fission gases (e.g., $\mathrm{Xe}, \mathrm{Ar}, \mathrm{Kr}$ ) but also volatile salt species that can form due to radiolysis among other things (e.g., $\mathrm{CsF}_{2}$ ). Such a system could leverage the existing AGR experiment infrastructure at ATR, which monitors fission-gas releases from TRISO fuel particles [17]. The fission-gas monitoring system for the AGR is illustrated in Figure 6. Nevertheless, R\&D work would still be needed to ensure the system could be leveraged for a more complex gaseous feed. In addition to gas sampling, a small salt-sampling mechanism can be envisaged to bleed salt at various intervals and freeze it away from the ATR core. This could provide valuable samples for PIE in order to study the evolution of the salt composition over time. Such a system is likely to be complex and require substantial R\&D investment to demonstrate it can operate reliably.

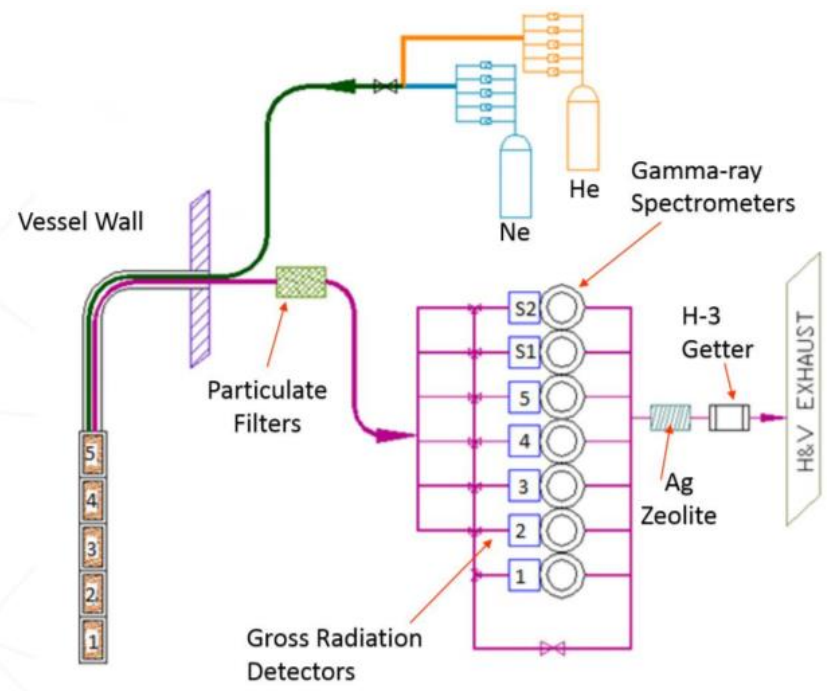

Figure 6. Illustration of the gas flow monitoring system for the AGR-1 experiment. The capsuled labeled 1 to 5 contain fuel particles and are within the ATR core (taken from [17]). 


\subsubsection{Post-irradiation Examination}

More flexibility is provided when examining salt characteristics after irradiation. While hot-cell manipulation can prove challenging, INL has a long history of expertise in operating under these conditions. The laboratory also has extensive background in salt handling for pyroprocessing applications. PIE analysis is unable to provide conclusive data on many salt aspects, such as effective thermal properties, because these will be affected by the continuous bubbling and precipitation effects within the salt. The insight is nevertheless expected to be invaluable, especially in terms of evaluating corrosion effects. Table 5 provides a summary of the different types of measurements that are anticipated to be conducted. The list is not exhaustive, but instrument decisions are unlikely to influence the design of VESIL significantly. A more detailed breakdown is therefore considered beyond the scope of this study.

Table 5. List of potential PIE measurements for VESIL. The item numbers in the second column correspond to the identified phenomena testing objectives in Table 3.

\begin{tabular}{|l|l|c|c|}
\hline \multicolumn{1}{|c|}{ Instrument } & \multicolumn{1}{|c|}{ Measurement } & $\begin{array}{c}\text { INL } \\
\text { Precedence }\end{array}$ & $\begin{array}{c}\text { R\&D } \\
\text { needs }\end{array}$ \\
\hline Flowmeter & Salt viscosity at a given burnup (\#1) & Yes & Low \\
\hline $\begin{array}{l}\text { Thermal needle } \\
\text { probes }\end{array}$ & Thermal conductivity at final burnup (\#1) & Yes & Low \\
\hline Calorimetric cells & Heat capacity at final burnup (\#1) & Yes & Low \\
\hline Ultrasonic testing & $\begin{array}{l}\text { Element plating on structure (\#5) } \\
\text { Material corrosion (\#4) } \\
\text { Localized freezing/thawing (\#8) } \\
\text { Component degradation (\#9,\#10) }\end{array}$ & Yes \\
\hline $\begin{array}{l}\text { Material } \\
\text { characterization }\end{array}$ & $\begin{array}{l}\text { Element plating on structure (\#5) } \\
\text { Material corrosion (\#4) } \\
\text { Heat exchanger degradation (\#9) }\end{array}$ & Yes & Low \\
\hline $\begin{array}{l}\text { Fiber-optic } \\
\text { methods }\end{array}$ & $\begin{array}{l}\text { Bulk salt properties (\#1) } \\
\text { Salt constituent characterization (\#2,\#3) } \\
\text { Radiative-heat transfer properties (\#1,\#9) } \\
\text { Material corrosion (\#4) }\end{array}$ & Yes & Medium \\
\hline
\end{tabular}

Measurement of hydraulic properties like thermal conductivity, viscosity, and melting temperature during PIE will be associated with a high degree of uncertainty. The impact of salt handling, fission-gas bubbles, and precipitate formation will not be captured in out-of-pile measurements. Nevertheless, evaluating these properties can still prove useful and will, at the very least, validate measurements conducted in situ. Thermal needle probes, calorimetric cells, and flow meters in gloveboxes are expected to be employed to this end. Minimal R\&D efforts are needed for these types of measurements.

Ultrasonic-testing techniques could provide valuable nondestructive examination of the loop structure following irradiation. The technique is expected to be employed to assess plating and corrosion effects. It can also be used for localized freezing/thawing evaluations during PIE. Material characterization (metallography), using electron microscopy or electrochemical measurements, would also be used for corrosion evaluation. It may prove useful to include sacrificial coupons within VESIL to test different material samples. These different approaches can also be leveraged to evaluate the degradation of heat exchangers, pumps, valves, and other components after irradiation. All these techniques are well established, and little to no challenge is anticipated for handling hot salts.

Fiber-optic-based measurements during PIE will be able to characterize salt optical properties. Pyrometers can be used to evaluate radiative-heat transfer, while laser-based spectroscopy methods can be leveraged for bulk salt properties evaluation. Optical spectroscopy can be employed to characterize the different salt species present at the final burnup state (this will $\backslash$ not account for precipitating and volatile 
species produced during irradiation). INL is currently conducting ongoing work on out-of-pile salt spectroscopy that can be directly leveraged for this purpose.

\subsubsection{Chemistry Control and Component Demonstration}

The last remaining items to discuss consist of general system demonstrations for the salt loop. Proving that these systems can operate in VESIL will provide the foundation for the design of larger components expected to operate inside a full-fledged reactor. Three categories are discussed here: the salt processing system (Item 7), the hydraulic/thermal components (Item 10), and the chemistry-control system (Item 11). Detailed characteristics of these systems will ultimately depend on the MSR concept selected for validation via VESIL.

Most MSR concepts expect some level of continuous salt processing during operations. This was the case for the MSRE, which actively separated protactinium from the fuel salt (to breed ${ }^{233} \mathrm{U}$ ), as well as other parasitic elements like rare-earth materials [18]. Table 6 summarizes some of the different removal rates envisaged for elements produced with the molten salt breeder reactor (MSBR) fuel salt. Complex diversion of the salt for processing will be impossible to conduct in a cartridge design of VESIL (design decisions are discussed in greater detail in Section 2.2). The bubbling of some elements (in a process similar to fluorination) can be envisioned, but would add to the overall complexity of the system. At the very least, some spontaneous volatilization of noble gases is expected to occur, along with the plating and precipitation of noble metals. These phenomena are inevitable to some extent. On the other hand, testing of polishing systems can be pursued post-irradiation to demonstrate feasibility.

Table 6. Processing and removal rates for different fission products in the MSBR (taken from Table 2 of ORNL-TM-3579 [19]).

\begin{tabular}{|l|l|l|}
\hline \multicolumn{1}{|c|}{ Elements } & \multicolumn{1}{c|}{ Type } & \multicolumn{1}{c|}{ Processing Time } \\
\hline $\mathrm{H}, \mathrm{Kr}, \mathrm{Xe}$ & Volatile fission gases & $50 \mathrm{~s}$ \\
\hline $\begin{array}{l}\mathrm{Zn}, \mathrm{Ga}, \mathrm{Ge}, \mathrm{As}, \mathrm{Se}, \mathrm{Nb}, \mathrm{Mo}, \\
\mathrm{Tc}, \mathrm{Ru}, \mathrm{Rh}, \mathrm{Pd}, \mathrm{Ag}, \mathrm{Cd}, \mathrm{In}, \\
\mathrm{Sn}, \mathrm{Sb}, \mathrm{Te}\end{array}$ & Precipitating/plating noble metals & $2.4 \mathrm{~h}$ \\
\hline $\mathrm{Br}, \mathrm{Rb}, \mathrm{Zr}, \mathrm{I}, \mathrm{Cs}, \mathrm{Ba}, \mathrm{Ce}$ & $\begin{array}{l}\text { Soluble halogens, alkali metals, } \\
\text { and alkaline earth elements }\end{array}$ & $10-15$ days \\
\hline $\begin{array}{l}\mathrm{Pr}, \mathrm{Nd}, \mathrm{Pm}, \mathrm{Sm}, \mathrm{Gd}, \mathrm{Tb}, \\
\mathrm{Dy}, \mathrm{Ho}, \mathrm{Er}\end{array}$ & Soluble rare-earth elements & 30 days \\
\hline $\mathrm{Eu}$ & 50 days \\
\hline
\end{tabular}

Due to the lack of existing off-the-shelf components that might be used with the salts considered for VESIL, a dedicated R\&D program to develop hydraulic components, such as pumps, valves, and seals, will likely be necessary. This has the added benefits of demonstrating the viability of certain component designs before they are deployed in a full-fledged reactor. These development efforts can learn from the components previously used for full-fledged MSRs (MSRE and ARE), those used in test reactor loops and experiments (see Section 1.2), as well as from the current components used for nitrite salts in concentrated solar systems. Substantial out-of-pile testing will be required before any of these systems is deployed within VESIL. Even then, detection mechanisms will need to ensure no leakages occur and systems function adequately. PIE will be conducted at the end of irradiation to assess wear and localized leakages. Non-hydraulic components that are not influenced by the presence of the salt, such as resistors for salt thawing, are expected to be more readily usable.

Salt-redox potential and impurities must be carefully controlled during the operation of VESIL. Impurities are known to drive corrosion rates in salt systems. This can be in the form of generated fission products, salt-transmutation products, and external contamination (e.g., water or air). Fluoride-salt radiolysis is known to be partially mitigated by the strong recombination potential, but this remains unverified for chloride salts. A dedicated chemical rebalancing system is required for VESIL. The type of 
system used will depend primarily on the salt type tested. The main approaches are either in the form of gas sparging, contacting the salt with a reducing metal, or adding soluble salt-redox buffers within the solution. [20] As mentioned before when discussing salt processing, fluorination can also be leveraged as a tool to remove salt impurities, thereby controlling the redox potential. This is typically achieved by injecting an $\mathrm{HF} / \mathrm{H}_{2}$ mixture or $\mathrm{CrF}_{2}$. Metal-rod control was demonstrated in the MSRE using beryllium. This was proven to limit the quantity of $\mathrm{UF}_{4}$ in the fuel salt. A further way of reducing the $\mathrm{UF}_{4} / \mathrm{UF}_{3}$ ratio in the MSRE was via periodic addition of $\mathrm{UF}_{3}$. Another option can involve the direct injection of $\mathrm{U}$ metal. While these methods relate specifically to a fluoride-based system, equivalent approaches can be envisaged for a chloride salt. Some of these approaches may be too complex for the purposes of VESIL, but a certain level of chemistry control is likely unavoidable.

\subsection{VESIL Design Considerations}

With testing objectives and instrumentation requirements identified, the design basis for VESIL can be established. This will help guide the neutronic analysis in Section 3 and provide the basis for the next stage of this project, where a preliminary design will be developed. The main guiding design criteria can be summarized as:

- Circulate fuel-bearing molten salt in an experiment position of the ATR core

- Employ a double-walled structure to ensure salt containment in the case of accidents

- Possess adequate instrumentation to continuously monitor performance and operating condition

- Ensure the experiment operates within ATR safety limits, with minimal impact to core performance

- Provide simplified access to the salt and structural material for PIE

- Employ adequate heat-exchange systems for controlling salt temperature

- Maintain continuous, online purge of volatile fission gases out of the loop during operation.

Different design considerations derive from these multiple points. An initial aspect is whether to rely on forced or natural circulation to satisfy the first criteria. Forced flow would be ideal to assess corrosion effects (Table 3 - Item 4) but would result in substantial cost increases. No readily available pump suitable for use in this type of an environment currently exists. A dedicated R\&D effort on the pump itself, in addition to valves and other components, would be required. Natural convective flow would be simpler and easier to implement, but would not reach the same velocities and could suffer from flow instabilities. Both options are considered at this stage of the project.

A second important design consideration is whether to opt for an external flow loop (e.g., closed loop in-reactor assembly in FFTF [21]) or to rely on a cartridge-type loop (such as the instrumented, independent, lead-cooled channel in BOR-60 [22]). Figure 7 illustrates how an external loop would exit the reactor pressure vessel, while a cartridge design is completely self-contained within the vessel boundary. For the purpose of VESIL, it was decided to select the latter option in light of the highly radioactive nature of the fuel salt, as well as the current facility limitations at the ATR. 

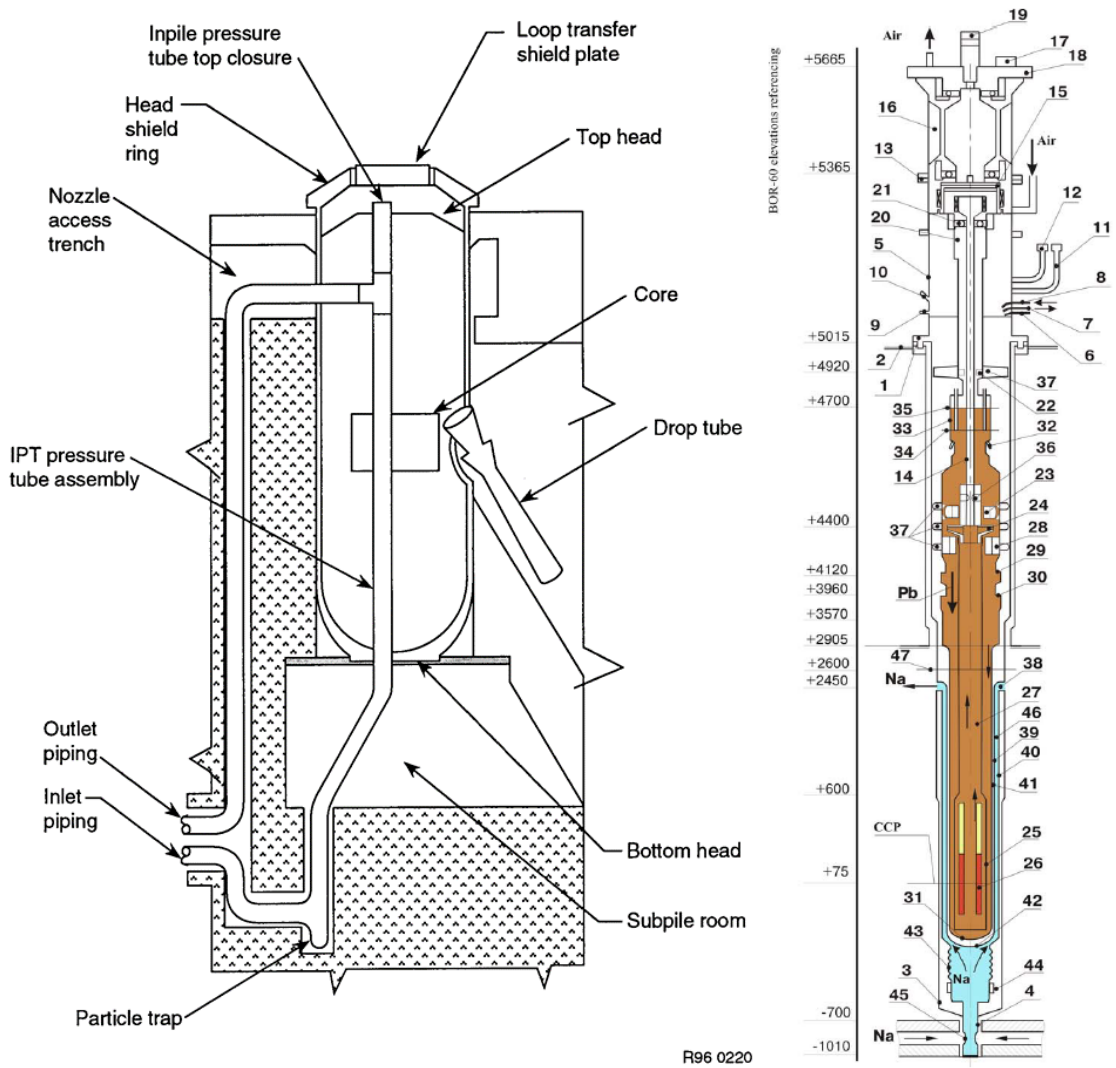

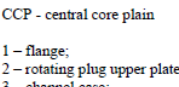

4 - tail;

5 - window;
- filling pipe connection

7 - gas outlet connection;

- immersible gas pipe connection 作 10 - ORS terminal;
1 - electric heater terminal connector 12 - measuring connector, 13 - flange of rotor lower bearing case; 14 - pump shaft; 15 - magnetic coupling, 16-electric motor case; 18 - pump drive cap; 19 - eye bolt; 0 - upper gas volume of the lead chamber 1 - ball bearing, - intermediate shaft suppor self-aligning plain bearing: $24-$ pump impeller,
25-FA shroud; 26 - fuel element mock-ups 27 - central tube; thermal converter cables and bypass tubes outlets eater cables and filling tube outlets; 1 - lead chamber bottom;
2 - bypass tubes inlets; 33 - oval tube; S element location; 38 - boss with side windows; 39 - internal tube; 41 - heat exchange 42 - semi-spherical botton 3 - bellows compensator; 44 - sodium flow meters; - side windows; 作

Figure 7. Example of an external flow loop in the ATR (left, taken from [23]), and an internal cartridgetype loop used in BOR-60 (right, taken from [24]).

The third design consideration regards a hydraulic-flow passage for the salt. VESIL could either opt for an annular configuration (good examples are the thermosyphon designed for HFIR [25] and the BOR-60 loop shown in Figure 7) or a pipe-flow configuration (similar to the MTR experiment shown in Figure 2 [4]). An annular design would be more compact, maximizing the irradiated salt volume while minimizing the risk of leakages. This was deemed more suitable for a natural convection flow. On the other hand, a forced-flow version of VESIL could leverage the smaller volume of a tubular flow to minimize pumping requirements (in light of the lower salt volume).

A fourth consideration is whether to rely on a gas-purge mechanism to continuously remove gaseous species or to simply allow these species to accumulate in a plenum. Reverting to a plenum would reduce cost, but introduce higher risks in a leakage scenario (due to the larger source term). On the other hand, an off-gas system would provide a continuous feed of valuable data on the status of salt irradiation (notably as it relates to Item 6). It is therefore recommended for VESIL.

A fifth design aspect concerns the temperature-control mechanism. Two options are available, and VESIL will likely employ some combination of them. Staggered resistors (resistive-heating) alongside the flow path would ensure a controlled thawing environment to start the operation of the loop (prior to the full operation of the ATR). Care must be taken to ensure that salt is melted from top to bottom in order to avoid damage caused by solid salt slugs. Resistors could also be employed to help induce natural circulation at startup as well. The other temperature-control mechanism would rely on a gas-injection module containing different gas mixtures. This is commonly used in ATR experiments and was leveraged for controlling temperature and monitoring potential leakages in the AGR experiments [26]. A gas-gap containing a binary gas mixture (e.g., helium and neon) could be used to separate the structure in contact with the salt from the barrier in contact with the ATR coolant. The conductivity within that gap could be 
increased or decreased by changing the binary gas composition within this gap with different thermal properties. This could provide enough flexibility to control salt temperature during operation.

The final design consideration regards the type of instruments and chemistry control system. This will depend strongly on the salt candidate (chloride vs. fluoride), as well as the program scope and priorities. A simpler version of VESIL would rely on more established in-situ measurement tools such as thermocouples, pressure gauges, flowmeters, electrochemical measurements, and $\mathrm{pH}$ sensors. A more complex version of VESIL could consider optical spectroscopy tools, but would require a dedicated R\&D effort to this end. The decision will depend on the final scope specified for VESIL as well as its allocated budget. Regardless of which in-situ measurement approach is selected, the majority of PIE evaluations highlighted in Section 2.1.2 will likely be conducted. Chemistry control during operations will prioritize simpler techniques to implement. Inserting a solid rod (of Be or $\mathrm{U}$ ) to dissolve specific radicals for redox control is expected to be feasible. A slightly more complex approach would rely on an injection tube with a tank of material external to the ATR vessel. This system could leverage the infrastructure required for the off-gas system. The decision of which chemistry control to opt for will strongly depend on the MSR concepted selected for testing in VESIL.

In summary, while most design characteristics cannot be clearly identified at this stage, two distinct versions of VESIL are currently under consideration. Their attributes are summarized in Table 7. Design A would rely on natural circulation of the salt and employ a concentric annular flow layout, as highlighted in Figure 8. Design B would be a forced circulation option that would allow the experiment to reach more representative velocity profiles of MSR concepts. It is likely to be tubular in order to reduce total salt volume and costs. Both designs would be cartridge-type (i.e., contained with the ATR vessel), use an off-gas system to manage gaseous fission products, and employ a similar temperature-control mechanism.

Table 7. Summary of the two design options for VESIL. The phenomena numbers correspond to those listed in Table 3. The cost estimates are preliminary and do not account for associated uncertainties.

\begin{tabular}{|l|l|l|}
\cline { 2 - 3 } \multicolumn{1}{c|}{} & \multicolumn{1}{c|}{ Design A } & \multicolumn{1}{c|}{ Design B } \\
\hline Flow & Natural & Forced \\
\hline Loop type & Cartridge & Cartridge \\
\hline Channel & Annular & Tubular \\
\hline Gas management & Off-gas system & Off-gas system \\
\hline Temperature control & Resistor + Gas blend & Resistor + Gas blend \\
\hline Phenomena fully addressed & $1,2,3,6,8,9,10$ & $1,2,3,4,5,6,8,9,10,11$ \\
\hline Phenomena partially addressed & $4,5,7,11$ & 7 \\
\hline Approximate cost estimate & $\$ 35-60 \mathrm{M}$ & $\$ 50-100 \mathrm{M}$ \\
\hline
\end{tabular}




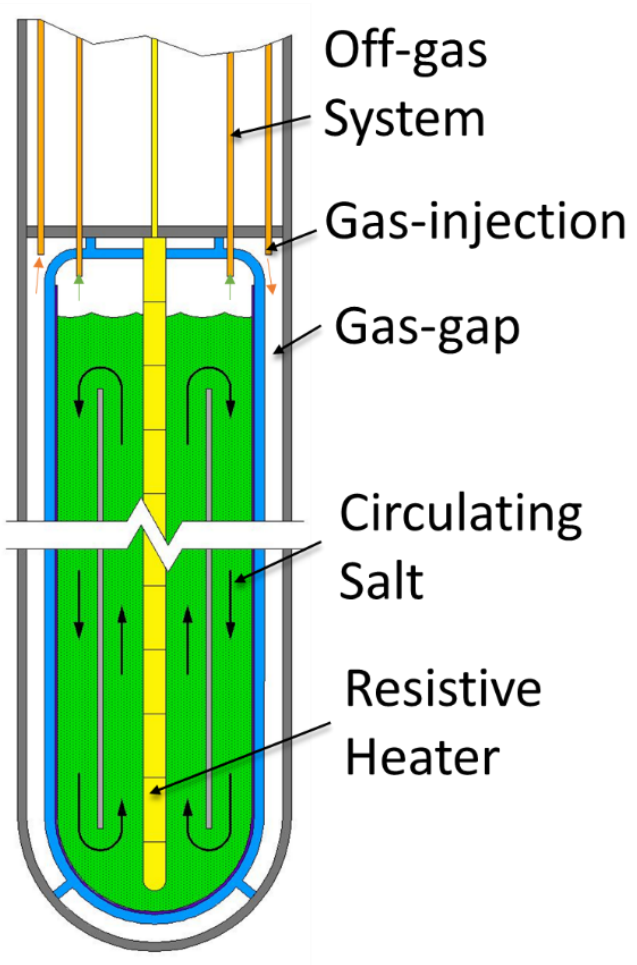

Design A

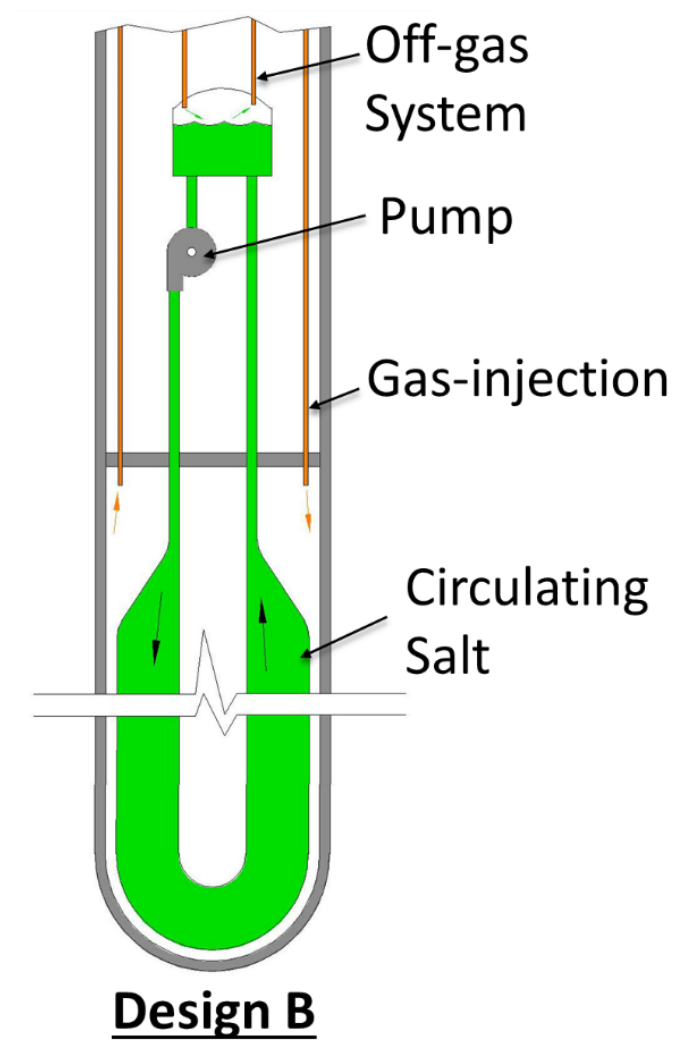

Figure 8. Illustration of the two different designs under consideration for VESIL. Design A relies on natural circulation for flow, while Design B uses a pump.

The cost estimates provided in Table 7 were based on expert judgement and historical precedence (mainly the AGR experiment). More information on the cost analysis is provided in Appendix A. Initial evaluations estimated the minimal base costs expected to be required for the experiments. Cost increases were then considered based on the potential expansion of the scope of the experiment. The costs are highly dependent on the design decisions, the instruments selected for in-situ measurement, and the required facilities for PIE. For instance, relying on forced circulation, or unproven technology such as optical spectroscopy is likely to increase the base costs by several millions of dollars in expenses. Design $\mathrm{B}$ will require a dedicated $\mathrm{R} \& \mathrm{D}$ campaign to test and qualify pumps, valves, and other components to operate under both flowing salt and high neutron/gamma irradiation. As a result, depending on the extent of the scope, Design A is expected to cost between $\$ 35-60 \mathrm{M}$, while Design B would cost \$50-100M. These values are very approximate, and do not account for the large uncertainties associated with cost estimation at this design stage (the range is due to the varying scope not uncertainties). It should be noted the costs are mainly labor-driven.

\section{NEUTRONIC ANALYSIS AND RESULTS}

\subsection{Modeling the Advanced Test Reactor}

The ATR has been in operation at INL since 1967. Its primary mission was to serve the U.S. Navy, but this has expanded in recent year to cover a wider variety of government and private research projects. Table 8 provides a summary of some of the operating specifications for the ATR. While the reactor is rated to $250 \mathrm{MW}_{\text {th }}$, it is seldom operated above $110 \mathrm{MW}_{\text {th. }}$. The length of an operating cycle has been slowly increasing over the years. It was closer to $40-50$ in the 2000 s, but has recently started reaching 
60 days. The 60-day effective full-power day (EFPD) value will be used in this analysis because VESIL is anticipated to be employed well into the future, when this cycle length will become fully established as the norm.

Table 8. ATR operating characteristics used in the analysis. Based on values from [27].

\begin{tabular}{|l|l|}
\hline Power & $110 \mathrm{MWth}$ \\
\hline EFPD & 60 days \\
\hline Number of flux traps & 9 \\
\hline Number of experiment positions & 68 \\
\hline Number of fuel assemblies & 40 \\
\hline Active length of assemblies & $121.92 \mathrm{~cm}$ \\
\hline Operating pressure & $2.7 \mathrm{MPa}$ \\
\hline Coolant $\mathbf{T}_{\text {in }} / \mathbf{T}_{\text {out }}$ & $52 / 71^{\circ} \mathrm{C}$ \\
\hline
\end{tabular}

A cross-section of the ATR showing the core layout and experiment positions is provided in Figure 9. Experiment positions can be grouped into four main categories: (1) A-position flux traps, (2) B-positions adjacent to the fuel plates, (3) I-positions behind the control rod drums, and (4) O-positions in the outer tank region. The innermost high-flux A-positions are in high demand and tend to be dedicated to specific irradiation programs. As such, they are considered unlikely options for VESIL. The B and I-positions are the primary VESIL location contenders. They are contained within the beryllium reflector and have varying sizes. The O-positions see a significant flux reduction relative to the I-positions due to the shielding effect of water outside the reflector tank wall. They are seldom used for experiments in light of their low-flux, but will still be considered in this VESIL study.

Among the three categories considered, smaller B-positions are the closest to the fuel plates and therefore record the highest flux. They are around $2.22 \mathrm{~cm}$ in diameter. Larger B-positions are around $3.81 \mathrm{~cm}$ and see around a 50\% reduction in total flux relative to their smaller counterparts. I-positions can range from 3.81 to 8.89 and to $12.7 \mathrm{~cm}$. With larger ones recording lower fluxes similarly to the Bposition. O-positions are less constricted in terms of space since they are located in a pool of water. Their dimensions are therefore variable.

B-positions see a notable fast flux, on the order of $10^{13}-10^{14} \mathrm{n} / \mathrm{cm}^{2}$-s. I-positions see very limited fast neutrons (closer to $10^{12} \mathrm{n} / \mathrm{cm}^{2}$-s), and O-positions even less $\left(10^{11} \mathrm{n} / \mathrm{cm}^{2}-\mathrm{s}\right)$. The overall flux tends to decrease by one order of magnitude from the $\mathrm{B}$, to the I, to the O-positions; with some variability measured within the different groupings (smaller B/I positions typically see higher flux levels). This tradeoff between experiment volume and flux level will be assessed in Section 3.2. 


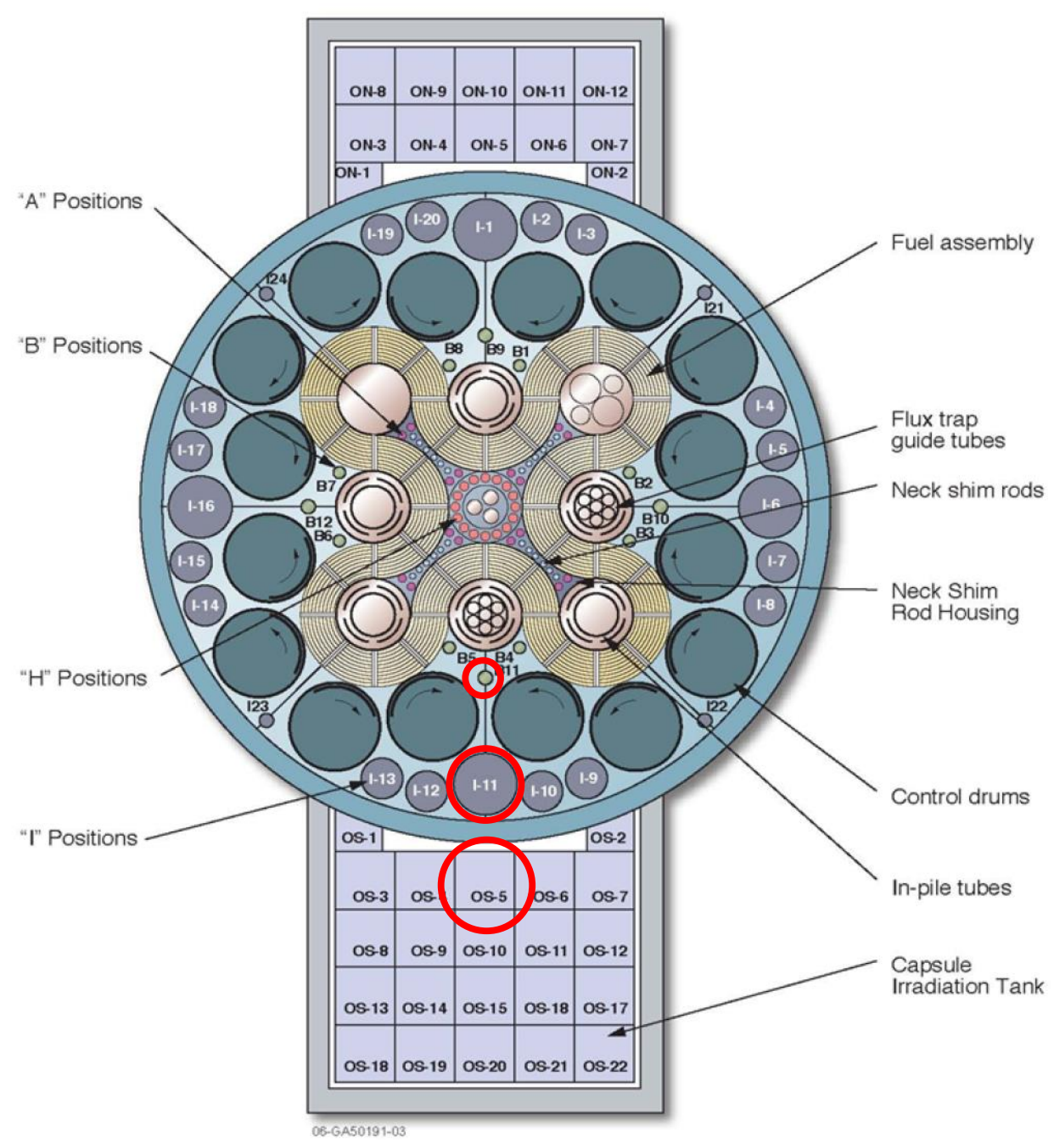

Figure 9. Diagram of the ATR core with the different experiment positions. The three positions used for the analysis in this report (B-11, I-11, and OS-5) are highlighted in red. (Taken from [27])

An MCNP6 model of the ATR based on the 94cic benchmark was used for the analysis [28]. A total of $3.75 \times 10^{7}$ particle histories (3,750 cycles, 250 of which were inactive) was deemed sufficient to analyse the B and I-positions, leading to a Monte Carlo standard deviation of $20 \mathrm{pcm}$ on the eigenvalue. Analysis of the O-position required an increase of up to $1.0 \times 10^{10}$ particle histories in order to get satisfactory statistical convergence on some energy bins in this position. Flux spectra were tallied at all of the B and I-positions (with the exception of the small I-positions), and two O-positions. Since O-positions were seldom used, no structure representing them currently exists in the MCNP model. The two positions considered were approximated as cylinders within the water pool as shown in Figure 10. 


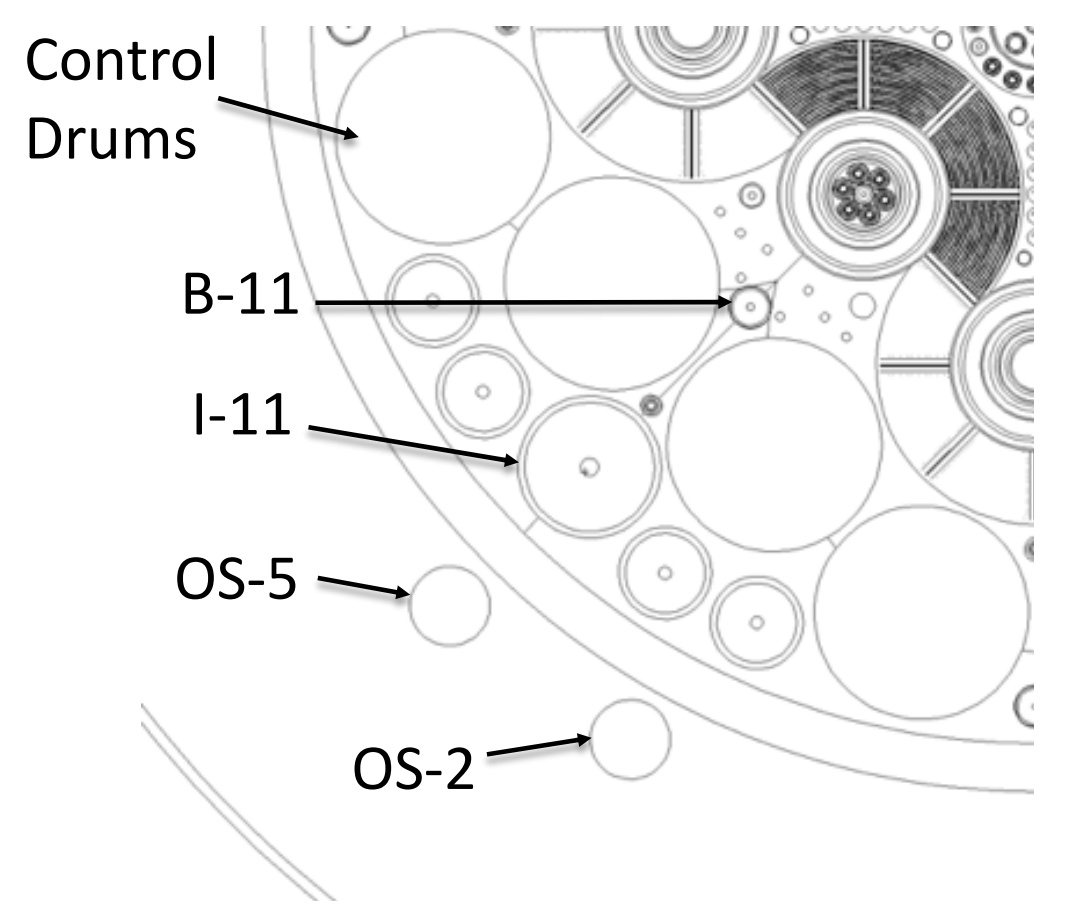

Figure 10. MCNP visualization of the added O-positions in the ATR water pool outside the beryllium reflector. These positions have never been previously modeled in MCNP at INL.

A summary of the total flux values (at $110 \mathrm{MW}_{\text {th }}$ ) is provided in Table 9. The variations observed within the same groupings are mainly due to different proximities to the fuel plates and variations in the power generation between the different ATR lobes (power splitting effect). It should be noted that these values are subject to change depending on the overall experiment loading in ATR and the power setting in each lobe. All B and I experimental positions were modeled in the simulation with beryllium dummy inserts, while the O-positions were filled with coolant water. The positions B-11 $\left(3.13 \times 10^{14} \mathrm{n} / \mathrm{cm}^{2}-\mathrm{s}\right)$, I$11\left(5.69 \times 10^{13} \mathrm{n} / \mathrm{cm}^{2}-\mathrm{s}\right)$, and OS-5 $\left(6.23 \times 10^{12} \mathrm{n} / \mathrm{cm}^{2}-\mathrm{s}\right)$ were selected for the reference analysis in the following sections (highlighted in Figure 9). The MCNP6 tallied values were relatively in-line with the ones quoted in the Users' Guide [27] (note that only fast/thermal fluxes are quoted in the report, not total values).

Table 9. Total tallied flux in the different ATR positions at $110 \mathrm{MW}_{\text {th }}$.

\begin{tabular}{|l|c|c|c|}
\hline \multicolumn{1}{|c|}{ Experiment Position } & $\begin{array}{c}\text { Diameter } \\
(\mathbf{c m})\end{array}$ & $\begin{array}{c}\text { Flux } \\
\left(\mathbf{n} / \mathbf{c m}^{2} \text {-s }\right)\end{array}$ & $\begin{array}{c}\text { Monte Carlo } \\
\text { standard deviation }\end{array}$ \\
\hline B-1 to B-8 & 2.22 & $5.57-7.55 \times 10^{14}$ & $0.35 \%$ \\
\hline B-9 to B-12 & 3.81 & $2.48-3.13 \times 10^{14}$ & $0.40 \%$ \\
\hline I-1, I-6, I-11, I-16 & 12.7 & $4.56-5.69 \times 10^{13}$ & $0.65 \%$ \\
\hline $\begin{array}{l}\text { I-2 to I-5, I-7 to I-10, I-12 to I-15, } \\
\text { I-18 to I-20 }\end{array}$ & 8.89 & $3.97-6.01 \times 10^{13}$ & $0.75 \%$ \\
\hline OS-2 & variable & $6.23 \times 10^{12}$ & $0.08 \%$ \\
\hline OS-5 & variable & $4.34 \times 10^{12}$ & $0.09 \%$ \\
\hline
\end{tabular}

Benchmark comparison for the spectra in the B and I regions was performed (no historical analysis on the O-position could be obtained). The spectra can have a notable impact on depletion analysis. For instance, an $85 \%$ deviance in burnup (and a correspondingly diverging mass of fission products) was recorded when using a standard PWR spectrum, versus the one computed for the ATR using MCNP6. A 44-group energy structure was selected for compatibility reasons with the COUPLE and ORIGEN 
modules in SCALE6.2.3 [29]. The generated lethargy-weighted flux spectrum was then compared to previously generated values by two experienced ATR modelers, one with 49 energy groups, the other 95 . The results for the B-positions are shown in Figure 11 and the ones for the I-position in Figure 12. Relatively good agreement is observed with the other two spectra provided. The generated 44 energygroup flux weighting was determined to be validated as a result.

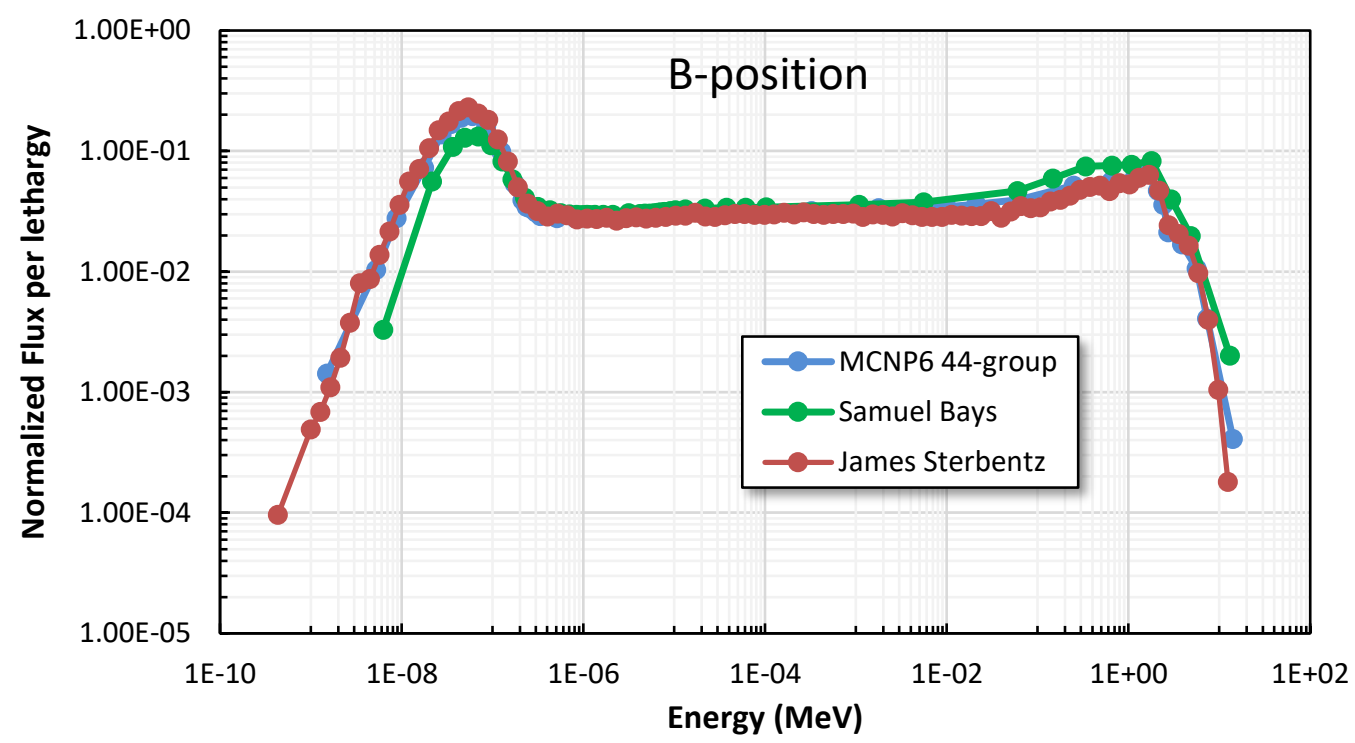

Figure 11. Comparison of the normalized flux per unit lethargy in the B-position of the ATR. Data from the other two curves was provided from two experienced ATR analysts ${ }^{1}$. Error bars are too small to appear in the plot.

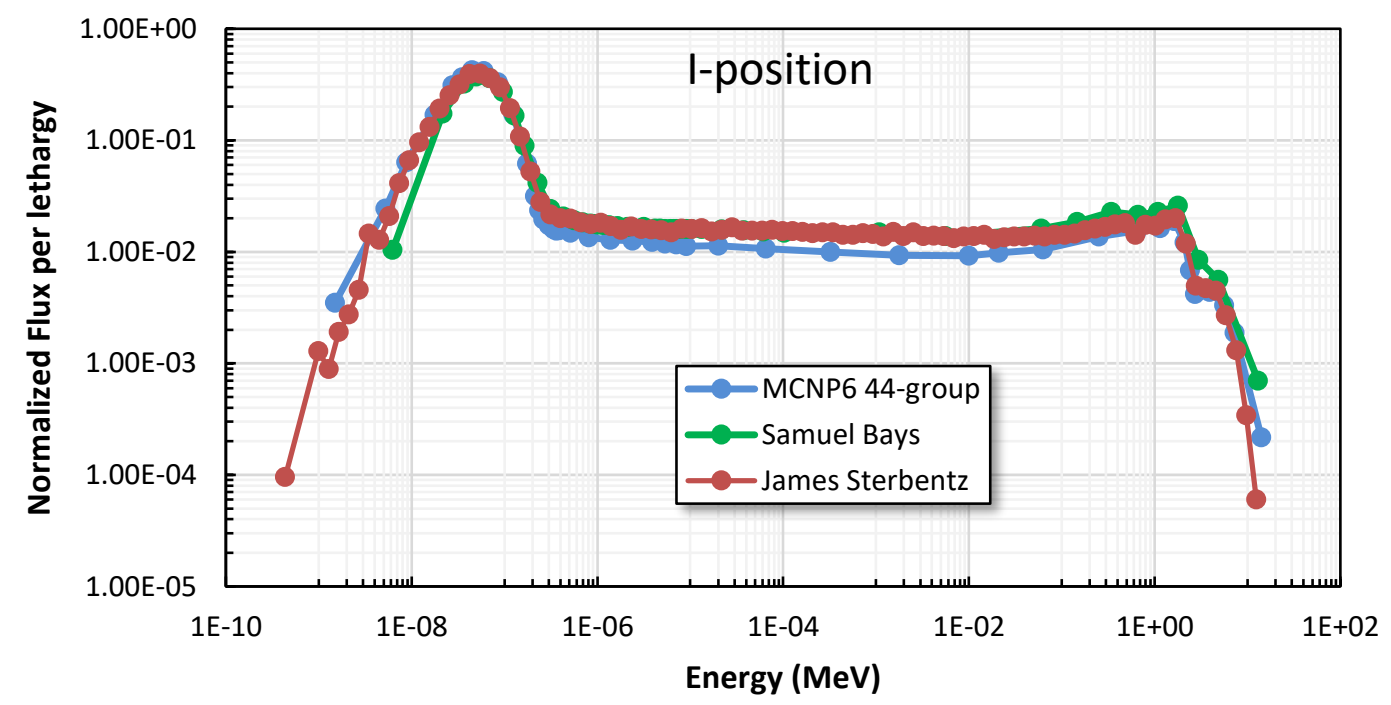

Figure 12. Comparison of the normalized flux per unit lethargy in the I-position of the ATR.

Analyses were also performed with a 238-group structure that is compatible with SCALE6.2.3. The finer group structure was found to provide no added gain in accuracy and was, therefore, not used in further analysis. The variation in spectra between the B, I, and O-positions is highlighted in Figure 13. It 
is apparent how the contribution of the fast flux is notably depressed the further away from the fuel plates, resulting in a much softer neutron spectrum. This increases the resulting ${ }^{235} \mathrm{U}$ fission cross-section between the B and I-position by a factor of 2.07, and between the B and O-positions by 2.40.

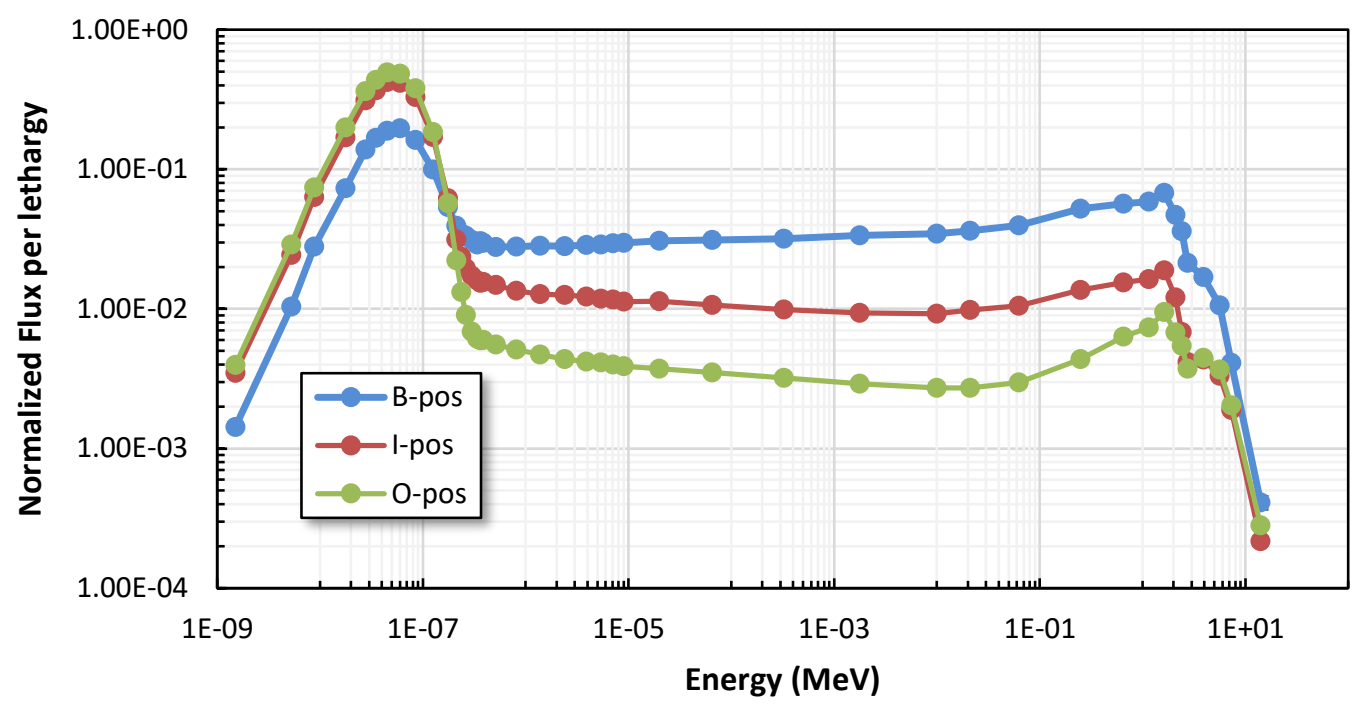

Figure 13. Comparison of the MCNP6 tallied normalized spectrum in the B-, I-, and O-position. Error bars are too small to appear in the plot.

The flux weighting was then used in COUPLE to generate three data libraries for ORIGEN depletion calculations, one for the B-position, another for the I-position, and a third for the O-position. ORIGEN input files to simulate an ATR cycle were then built using the specifications of Table 8. Different salt compositions were considered, and each was evaluated under the two irradiation conditions.

\subsection{Parametric Study of Salt Irradiation}

Following a literature survey and discussion with vendors, a total of eight distinct salt compositions were considered in this study. Their corresponding acronyms are (1) FLiBe, simple non-fuel-bearing salt [30], (2) ARE, salt composition of the Aircraft Reactor Experiment [31], (3) MSRE, salt irradiated in the Molten Salt Reactor Experiment [32], (4) MSBR, proposed primary salt of the Molten Salt Breeder Reactor [33], (5) LFTR1, primary salt proposed by the Flibe Energy corporation [34], (6) LFTR2, blanket salt proposed in the Flibe Energy concept, (7) TAP, the salt composition of the Transatomic Power MSR [35], and (8) REBUS, a chloride-salt concept loosely based on an MSR concept developed by EDF [36]. A summary of the eight molar composition considered is provided in Table 10. Density values are selected to be representative of the operating (and, therefore, testing) conditions. Interpolation between available data was required for the reference REBUS salt constitution.

Table 10. Candidate salts considered in the parametric study.

\begin{tabular}{|l|c|c|c|}
\hline \multicolumn{1}{|c|}{ Salt } & $\begin{array}{c}\text { Density }\left(\mathbf{g} / \mathbf{c m}^{3}\right) \\
\text { at operating T }\end{array}$ & \multicolumn{1}{c|}{ Constituent Molar Fractions } & References \\
\hline FLiBe & 1.950 & $67.0 \% \mathrm{LiF}-33.0 \% \mathrm{BeF}_{2}$ & {$[37,30]$} \\
\hline ARE & 3.273 & $53.1 \% \mathrm{NaF}-40.7 \% \mathrm{ZrF}_{2}-6.2 \% \mathrm{UF}_{2}$ & {$[31]$} \\
\hline MSRE & 2.275 & $65.0 \% \mathrm{LiF}-29.1 \% \mathrm{BeF}_{2}-5.0 \% \mathrm{ZrF}_{4}-0.9 \% \mathrm{UF}_{4}$ & {$[32]$} \\
\hline MSBR & 3.383 & $71.6 \% \mathrm{LiF}-16.0 \% \mathrm{BeF}_{2}-0.4 \% \mathrm{UF}_{4}-12.0 \% \mathrm{ThF}_{4}$ & {$[33]$} \\
\hline LFTR1 & 1.979 & $66.0 \% \mathrm{LiF}-33.0 \% \mathrm{BeF}_{2}-10.0 \% \mathrm{UF}_{4}$ & {$[34]$} \\
\hline LFTR2 & 4.750 & $75.0 \% \mathrm{LiF}-25.0 \% \mathrm{ThF}_{4}$ & {$[34]$} \\
\hline TAP & 5.010 & $72.5 \% \mathrm{LiF}-27.5 \% \mathrm{UF}_{4}$ & {$[35]$} \\
\hline REBUS & 3.444 & $55.0 \% \mathrm{NaCl}-45.0 \% \mathrm{UCl}_{3}$ & {$[38,36]$} \\
\hline
\end{tabular}


Salts from other U.S. companies highlighted in Table 1, such as Yellowstone Energy, Terrestrial Energy, Terrapower, and Elysium, were not considered due to the proprietary nature of the salt compositions. However, the vast range of fluoride-salt concepts is expected to encompass the design space of these other vendors. For instance, the ARE salt is expected to be representative of proposed concepts that use fluoride-based salts without any lithium or beryllium. Similarly, the REBUS chloride salt is expected to be representative of the fast-spectrum designs pursued in the U.S.

Only ${ }^{235} \mathrm{U}$ was considered as the initial startup fissile material (no $\mathrm{Pu}$ or transuranics). This provides a more adequate basis for comparison between the cases and avoids the potential difficulties with accessing and handling plutonium and minor actinides. However, both ${ }^{238} \mathrm{U}$ and ${ }^{232} \mathrm{Th}$ are considered as fertile isotopes. Throughout the analysis of Section 3.2.1, an enrichment of 5\% is selected for all cases; different enrichment levels are considered in Section 3.2.2. Similarly, no enrichment of chlorine or lithium is considered at first, but this was further investigated in Section 3.2.2.

\subsubsection{Summary of ORIGEN Depletion Results}

The results of the salt-irradiation parametric studies are summarized in the two tables below. A more comprehensive overview of the results is provided in Appendix B. The eight salts considered were simulated under one cycle of irradiation inside the three ATR positions using ORIGEN 6.2.3. Production rate of key elements are highlighted, notably Te (a corrosion driver), volatile gases, and precipitating noble metals. Data on activity after irradiation (both in watts and curies) are provided at the end of irradiation, as well as for one and ten days of subsequent decay. It should be noted that values are not intended to be representative and are mainly useful for comparisons. For instance, some tritium production rates and power densities are expected to be prohibitive and not feasible for an ATR experiment. This will be investigated in greater detail in Section 3.2.2. 
Table 11. Production rates per unit of irradiated salt volume $\left(\mathrm{cm}^{3}\right)$ in the B, I and O-positions of the ATR, after one cycle. Concentrations lower than $10^{-6}$ $\mathrm{g} / \mathrm{cm}^{3}$ are cutoff from the results.

\begin{tabular}{|c|c|c|c|c|c|c|c|c|c|c|}
\hline & & \multicolumn{9}{|c|}{ mass generated per volume of irradiated salt ( $\left.\mathrm{mg} / \mathrm{cm}^{3}-\mathrm{salt}\right)$} \\
\hline & & ${ }^{3} \mathrm{H}$ & $\mathrm{Te}$ & Mo & Cs & $\mathrm{Xe}$ & ${ }^{233} \mathrm{U}$ & $\mathrm{Pu}$ & All volatile & All precipitate \\
\hline \multirow{3}{*}{ FLiBe } & $\mathbf{B}$ & 3.67 & - & - & - & - & - & - & 8.57 & - \\
\hline & I & 1.61 & - & - & - & - & - & - & 3.75 & - \\
\hline & $\mathbf{O}$ & 0.15 & - & - & - & - & - & - & 0.36 & - \\
\hline \multirow{3}{*}{ ARE } & B & - & 0.11 & 5.48 & 0.48 & 1.09 & - & 4.80 & 1.17 & 1.47 \\
\hline & I & - & 0.03 & 1.92 & 0.18 & 0.37 & - & 0.54 & 0.41 & 0.47 \\
\hline & $\mathbf{O}$ & - & - & 0.18 & 0.02 & 0.03 & - & 0.03 & 0.03 & 0.04 \\
\hline \multirow{3}{*}{ MSRE } & B & 3.27 & 0.03 & 1.46 & 0.13 & 0.29 & - & 1.28 & 7.96 & 0.39 \\
\hline & $\mathbf{I}$ & 1.43 & 0.01 & 0.51 & 0.05 & 0.10 & - & 0.14 & 3.46 & 0.13 \\
\hline & O & 0.14 & - & 0.05 & 0.01 & 0.01 & - & 0.01 & 0.33 & 0.01 \\
\hline \multirow{3}{*}{ MSBR } & B & 3.48 & 0.03 & 1.04 & 0.10 & 0.22 & 5.17 & 0.55 & 8.37 & 0.26 \\
\hline & I & 1.52 & 0.01 & 0.25 & 0.02 & 0.05 & 1.23 & 0.06 & 3.62 & 0.06 \\
\hline & $\mathbf{O}$ & 0.15 & - & 0.02 & - & - & 0.10 & - & 0.35 & - \\
\hline \multirow{3}{*}{ LFTR1 } & B & 1.88 & 0.18 & 9.02 & 0.81 & 1.82 & - & 8.05 & 6.37 & 2.44 \\
\hline & I & 0.82 & 0.06 & 3.21 & 0.30 & 0.63 & - & 0.91 & 2.61 & 1.13 \\
\hline & $\mathbf{O}$ & 0.08 & 0.01 & 0.30 & 0.03 & 0.05 & - & 0.05 & 0.24 & 0.07 \\
\hline \multirow{3}{*}{ LFTR2 } & B & 3.41 & 0.03 & 0.84 & 0.08 & 0.19 & 10.09 & - & 8.19 & 0.19 \\
\hline & I & 1.49 & - & 0.07 & 0.01 & 0.02 & 2.40 & - & 3.51 & 0.02 \\
\hline & $\mathbf{O}$ & 0.14 & - & - & - & - & 0.20 & - & 0.34 & - \\
\hline \multirow{3}{*}{ TAP } & B & 3.19 & 0.75 & 38.25 & 3.45 & 7.74 & - & 34.16 & 15.79 & 10.37 \\
\hline & I & 1.40 & 0.25 & 13.63 & 1.28 & 2.65 & - & 3.85 & 6.15 & 3.36 \\
\hline & $\mathbf{O}$ & 0.13 & 0.02 & 1.26 & 0.15 & 0.21 & - & 0.20 & 0.55 & 0.31 \\
\hline \multirow{3}{*}{ REBUS } & B & - & 0.47 & 24.18 & 2.18 & 4.89 & - & 21.60 & 5.28 & 6.55 \\
\hline & I & - & 0.16 & 8.61 & 0.81 & 1.68 & - & 2.43 & 1.83 & 2.13 \\
\hline & O & - & 0.01 & 0.79 & 0.09 & 0.13 & - & 0.13 & 0.15 & 0.19 \\
\hline
\end{tabular}


Table 12. Parametric evaluation per unit of irradiated salt volume $\left(\mathrm{cm}^{3}\right)$ in the $\mathrm{B}, \mathrm{I}$, and O-positions of the ATR. Very low values are not reported.

\begin{tabular}{|c|c|c|c|c|c|c|c|c|c|c|}
\hline & \multirow{2}{*}{$\begin{array}{l}\text { BOC power } \\
\left(\mathrm{W} / \mathrm{cm}^{3}\right)\end{array}$} & \multirow{2}{*}{$\begin{array}{c}\text { BOC }{ }^{1} n \\
\text { prod./abs. }\left(k_{\infty}\right)\end{array}$} & \multirow{2}{*}{$\begin{array}{c}\text { Burnup } \\
(\mathrm{MWd} / \mathrm{kg})\end{array}$} & \multicolumn{3}{|c|}{ Activity $\left(\mathrm{kCi} / \mathrm{cm}^{3}\right)$} & \multicolumn{3}{|c|}{ Decay Heat $\left(\mathrm{W} / \mathrm{cm}^{3}\right)$} \\
\hline & & & & & at $\mathrm{EOC}$ & 1-day after & 10-day after & at EOC & 1-day after & 10-day after \\
\hline \multirow{3}{*}{ FLiBe } & B & 145 & - & - & 0.04 & 0.04 & 0.04 & 0.22 & - & - \\
\hline & $\mathbf{I}$ & 55 & - & - & 0.02 & 0.02 & 0.02 & 0.07 & - & - \\
\hline & $\mathbf{O}$ & 5 & - & - & - & 0.00 & 0.00 & 0.01 & - & - \\
\hline \multirow{3}{*}{ ARE } & B & 108 & 0.99 & 14.97 & 0.68 & 0.15 & 0.04 & 7.30 & 0.66 & 0.16 \\
\hline & $\mathbf{I}$ & 40 & 1.34 & 5.21 & 0.20 & 0.04 & 0.01 & 2.47 & 0.19 & 0.05 \\
\hline & O & 4 & 1.51 & 0.48 & 0.02 & 0.00 & 0.00 & 0.24 & 0.02 & 0.00 \\
\hline \multirow{3}{*}{ MSRE } & $\mathbf{B}$ & 158 & 0.02 & 67.15 & 0.21 & 0.07 & 0.04 & 2.02 & 0.14 & 0.04 \\
\hline & $\mathbf{I}$ & 59 & 0.01 & 28.03 & 0.06 & 0.02 & 0.02 & 0.68 & 0.04 & 0.01 \\
\hline & $\mathbf{O}$ & 5 & 0.01 & 2.67 & 0.01 & 0.00 & 0.00 & 0.06 & - & - \\
\hline \multirow{3}{*}{ MSBR } & B & 155 & 0.03 & 5.35 & 0.51 & 0.19 & 0.14 & 3.05 & 0.43 & 0.28 \\
\hline & I & 57 & 0.01 & 2.11 & 0.11 & 0.05 & 0.04 & 0.61 & 0.09 & 0.06 \\
\hline & $\mathbf{O}$ & 5 & 0.01 & 0.20 & 0.01 & 0.00 & 0.00 & 0.05 & 0.01 & 0.00 \\
\hline \multirow{3}{*}{ LFTR1 } & B & 254 & 0.21 & 19.64 & 1.12 & 0.25 & 0.08 & 11.54 & 0.87 & 0.26 \\
\hline & $\mathbf{I}$ & 94 & 0.14 & 7.26 & 0.32 & 0.06 & 0.03 & 3.89 & 0.24 & 0.09 \\
\hline & $\mathbf{O}$ & 8 & 0.13 & 0.67 & 0.03 & 0.01 & 0.00 & 0.37 & 0.02 & 0.01 \\
\hline \multirow{3}{*}{ LFTR2 } & B & 144 & 0.03 & 2.83 & 0.80 & 0.30 & 0.23 & 4.24 & 0.73 & 0.51 \\
\hline & I & 53 & 0.01 & 1.05 & 0.16 & 0.07 & 0.06 & 0.60 & 0.14 & 0.11 \\
\hline & $\mathbf{O}$ & 5 & - & 0.10 & 0.01 & 0.01 & 0.00 & 0.03 & 0.01 & 0.01 \\
\hline \multirow{3}{*}{ TAP } & B & 887 & 0.40 & 17.03 & 4.70 & 1.03 & 0.29 & 48.61 & 3.70 & 1.12 \\
\hline & I & 329 & 0.31 & 6.01 & 1.34 & 0.25 & 0.10 & 16.41 & 1.01 & 0.38 \\
\hline & O & 29 & 0.30 & 0.55 & 0.12 & 0.02 & 0.01 & 1.58 & 0.09 & 0.03 \\
\hline \multirow{3}{*}{ REBUS } & B & 541 & 0.35 & 16.68 & 2.98 & 0.65 & 0.18 & 31.01 & 2.43 & 0.71 \\
\hline & $\mathbf{I}$ & 201 & 0.34 & 5.86 & 0.85 & 0.15 & 0.06 & 10.48 & 0.67 & 0.24 \\
\hline & $\mathbf{O}$ & 18 & 0.37 & 0.54 & 0.08 & 0.01 & 0.01 & 1.01 & 0.06 & 0.02 \\
\hline
\end{tabular}


For the purpose of this analysis, the elements lumped into the volatile/precipitate categories are based on those highlighted in Table 6 and on previous research in this area [39]. The elements assumed to be volatile are $\mathrm{H}, \mathrm{He}, \mathrm{Kr}$, $\mathrm{Ar}$, and $\mathrm{Xe}$, while those assumed to precipitate are $\mathrm{Te}, \mathrm{Mo}, \mathrm{Sb}, \mathrm{Ag}, \mathrm{Pd}, \mathrm{Rh}, \mathrm{Ru}, \mathrm{Tc}$, and $\mathrm{Nb}$. No estimates of volatile or precipitating fluoride/chloride species are included in the quoted results. All of the produced species are assumed to be completely insoluble and released as a gas or a solid (in reality, some of these elements are likely to be partially soluble in a given salt). This is an approximation, and the results are only intended to be used for comparative purposes and to provide a first-order estimate of the quantities of relevant elements produced.

While the REBUS salt is proposed to be used in fast-spectrum reactors, thermal-spectrum irradiation inside the ATR is still valuable to study different aspects driven by fission reactions and fission products (rather than neutron energy). As such, most of the items in Table 3 can still be evaluated in the ATR. The main anticipated limitation of thermal-spectrum irradiation regard providing representative structural material damage (i.e., dpa). This may need to be investigated separately inside a fast-flux facility.

The results highlight why experiment tailoring will be required in many of these cases. For instance, the heat generation at the end of irradiation for the REBUS salt is two orders of magnitude higher than that of FLiBe. This will directly impact experimental handling and will need to be carefully considered. Tritium production also appears to be high in some cases. Enriched lithium is likely to be required in order to adhere to ATR safety requirement. Interestingly, ${ }^{6} \mathrm{Li}$ heating drives the majority of heat generation in cases such as the MSRE. While the ${ }^{6} \mathrm{Li}$ reaction highlighted below releases around 40 times less energy than ${ }^{235} \mathrm{U}$ fission, this is compensated by the ${ }^{6} \mathrm{Li}$ atom density being more than 100 times larger than the fissile uranium isotope inside the MSRE salt. This highlights the need to carefully account for these competing effects.

$$
{ }_{3}^{6} \mathrm{Li}+{ }_{0}^{1} \mathrm{n} \rightarrow{ }_{2}^{4} \mathrm{He}+{ }_{1}^{3} \mathrm{H}+4.78 \mathrm{MeV}
$$

A tradeoff between the ATR position flux and volume impacts which position to select for VESIL. While B-positions have higher flux levels, the I-positions can compensate by offering larger experiment volume for instance. Assuming that $30 \%$ of the available volume for the B and I-positions is occupied by salt, total quantities of fission products produced can be estimated. For comparative purposes the Oposition was assumed equal to that of I-11 (there are no size constructions in this region of the ATR). Table 13 highlights how salts in the I-position generate more Xe, for instance, than in the B-position. Total quantities produced are more relevant in certain phenomena, such as volatile gas production (Item 6 in Table 3) and the formation of precipitates and noble metal plating (Item 5). Because these elements exit the salt in one form or another, total mass is more relevant than their concentration within the salt. These phenomena might be more desirable to assess inside I-positions. On the other hand, corrosion effects (Item 4) and solubility limits (Item 2) are driven by concentrations. As a result, fission products per unit of salt volume are more relevant for these types of measurements. The B-positions might prove more desirable here. In light of the reduced flux in the $\mathrm{O}$ regions, these positions produce only trace amounts of fission products for most cases considered. They are likely to be of limited interest except for highactinide bearing salts (e.g., TAP and REBUS). In order to decide which position to select, the VESIL program will to need weigh the importance of items in Table 3 relative to each other. The final decision will strongly depend on the salt type and MSR concept considered.

It should be noted that some of the power-generation levels quoted in Table 13 (as well as in Table 12) are unrealistic and will be prohibitive for an ATR experiment. The uranium enrichment in the REBUS or TAP cases, for instance, will need to be reduced in order to reach more manageable power levels. At this stage, the results are only relevant from a comparative standpoint. The estimates also do not account for any fission reactions occurring above the height of the core (the loop is likely to extend beyond the active core region). 
Table 13. Total quantity of element produced after 1 ATR cycle, assuming that the salt occupies $30 \%$ of the available experiment-position volume. Activity and decay heat values are at EOC.

\begin{tabular}{|c|c|c|c|c|c|c|c|c|c|c|c|c|}
\hline & & $\begin{array}{l}\text { salt mass } \\
(\mathrm{kg})\end{array}$ & $\begin{array}{l}\mathrm{Xe} \\
(\mathrm{g})\end{array}$ & $\begin{array}{l}\text { Te } \\
(\mathrm{g}) \\
\end{array}$ & $\begin{array}{l}\text { Mo } \\
(\mathrm{g}) \\
\end{array}$ & $\begin{array}{l}\text { Cs } \\
(\mathrm{g}) \\
\end{array}$ & $\begin{array}{l}\mathrm{Pu} \\
(\mathrm{g})\end{array}$ & $\begin{array}{c}\text { All volatile } \\
(\mathrm{g})\end{array}$ & $\begin{array}{l}\text { All precipitate } \\
(\mathrm{g})\end{array}$ & $\begin{array}{c}\text { BOC power } \\
(\mathrm{kW})\end{array}$ & $\begin{array}{c}\text { Activity } \\
(\mathrm{kCi})\end{array}$ & $\begin{array}{c}\text { Decay heat } \\
(\mathrm{kW})\end{array}$ \\
\hline \multirow{3}{*}{ FLiBe } & B & 0.86 & 0.00 & 0.00 & 0.00 & 0.00 & 0.00 & 3.80 & 0.00 & 64.22 & 18.21 & 0.10 \\
\hline & I & 9.60 & 0.00 & 0.00 & 0.00 & 0.00 & 0.00 & 18.48 & 0.00 & 269.32 & 84.26 & 0.36 \\
\hline & $\mathbf{O}$ & 9.60 & 0.00 & 0.00 & 0.00 & 0.00 & 0.00 & 1.78 & 0.00 & 23.75 & 8.02 & 0.03 \\
\hline \multirow{3}{*}{ ARE } & B & 1.45 & 0.48 & 0.05 & 0.24 & 0.21 & 2.13 & 0.52 & 0.65 & 47.74 & 3371.16 & 35.95 \\
\hline & I & 16.11 & 1.83 & 0.17 & 0.95 & 0.88 & 2.66 & 2.00 & 2.33 & 196.03 & 965.93 & 12.18 \\
\hline & $\mathbf{O}$ & 16.11 & 0.15 & 0.02 & 0.09 & 0.10 & 0.14 & 0.16 & 0.21 & 17.24 & 89.31 & 1.16 \\
\hline \multirow{3}{*}{ MSRE } & B & 1.01 & 0.13 & 0.01 & 0.06 & 0.06 & 0.57 & 3.53 & 0.17 & 69.93 & 1042.53 & 9.93 \\
\hline & I & 11.20 & 0.49 & 0.05 & 0.25 & 0.24 & 0.71 & 17.02 & 0.62 & 292.18 & 319.33 & 3.35 \\
\hline & $\mathbf{O}$ & 11.20 & 0.04 & 0.00 & 0.02 & 0.03 & 0.04 & 1.63 & 0.06 & 25.76 & 29.79 & 0.32 \\
\hline \multirow{3}{*}{ MSBR } & B & 1.50 & 0.10 & 0.01 & 0.05 & 0.04 & 0.24 & 3.71 & 0.12 & 68.46 & 2491.00 & 15.04 \\
\hline & I & 1.50 & 0.02 & 0.00 & 0.01 & 0.01 & 0.03 & 1.60 & 0.03 & 25.44 & 537.43 & 2.98 \\
\hline & $\mathbf{O}$ & 1.50 & 0.00 & 0.00 & 0.00 & 0.00 & 0.00 & 0.15 & 0.00 & 2.24 & 42.24 & 0.22 \\
\hline \multirow{3}{*}{ LFTR1 } & B & 0.88 & 0.81 & 0.08 & 0.40 & 0.36 & 3.57 & 2.82 & 1.08 & 112.48 & 5521.05 & 56.81 \\
\hline & I & 0.88 & 0.28 & 0.03 & 0.14 & 0.13 & 0.40 & 1.16 & 0.50 & 41.86 & 1578.98 & 19.17 \\
\hline & $\mathbf{O}$ & 0.88 & 0.02 & 0.00 & 0.01 & 0.02 & 0.02 & 0.11 & 0.03 & 3.68 & 146.53 & 1.84 \\
\hline \multirow{3}{*}{ LFTR2 } & $\mathbf{B}$ & 2.10 & 0.09 & 0.01 & 0.04 & 0.04 & 0.00 & 3.63 & 0.08 & 63.89 & 3953.15 & 20.88 \\
\hline & I & 23.38 & 0.08 & 0.01 & 0.03 & 0.03 & 0.00 & 17.27 & 0.08 & 260.09 & 766.79 & 2.96 \\
\hline & $\mathbf{O}$ & 23.38 & 0.00 & 0.00 & 0.00 & 0.00 & 0.00 & 1.65 & 0.00 & 22.85 & 56.11 & 0.16 \\
\hline \multirow{3}{*}{ TAP } & $\mathbf{B}$ & 2.22 & 3.43 & 0.33 & 1.69 & 1.53 & 15.13 & 7.00 & 4.59 & 392.98 & 23138.69 & 239.32 \\
\hline & I & 24.66 & 13.05 & 1.22 & 6.71 & 6.28 & 18.95 & 30.27 & 16.56 & 1619.79 & 6583.91 & 80.78 \\
\hline & $\mathbf{O}$ & 24.66 & 1.05 & 0.11 & 0.62 & 0.73 & 1.00 & 2.70 & 1.51 & 142.50 & 610.69 & 7.76 \\
\hline \multirow{3}{*}{ REBUS } & $\mathbf{B}$ & 1.53 & 2.17 & 0.21 & 1.07 & 0.97 & 9.57 & 2.34 & 2.90 & 239.88 & 14683.09 & 152.67 \\
\hline & I & 16.96 & 8.25 & 0.77 & 4.24 & 3.97 & 11.98 & 8.99 & 10.47 & 988.03 & 4175.81 & 51.60 \\
\hline & $\mathbf{O}$ & 16.96 & 0.66 & 0.07 & 0.39 & 0.46 & 0.64 & 0.73 & 0.95 & 86.90 & 386.95 & 4.95 \\
\hline
\end{tabular}




\subsubsection{Experiment Tailoring}

As highlighted in the previous section, experimental parameters will need to be tailored to match the desired neutronic operating conditions. Uranium enrichment can be fine-tuned to the power density in the reactor design, or even increased to accelerate burnup. The enrichment in salts intended for fast-MSR concepts will likely have to be reduced due to their higher actinide inventory combined with the higher cross-sections in the thermal spectrum of the ATR. To showcase the flexibility of ATR positions, Figure 14 demonstrates the wide range of energy densities that can be obtained for a given salt composition. Note that these values are approximate and are computed manually based on the MCNP6 tallied ${ }^{235} \mathrm{U}$ fission cross-section. No ORIGEN calculations were run, but the REBUS results agree within $10 \%$ with the values quoted in Table 11 . Two additional experimental positions for each category are also shown to highlight the notable differences within the B, I, and O-positions.

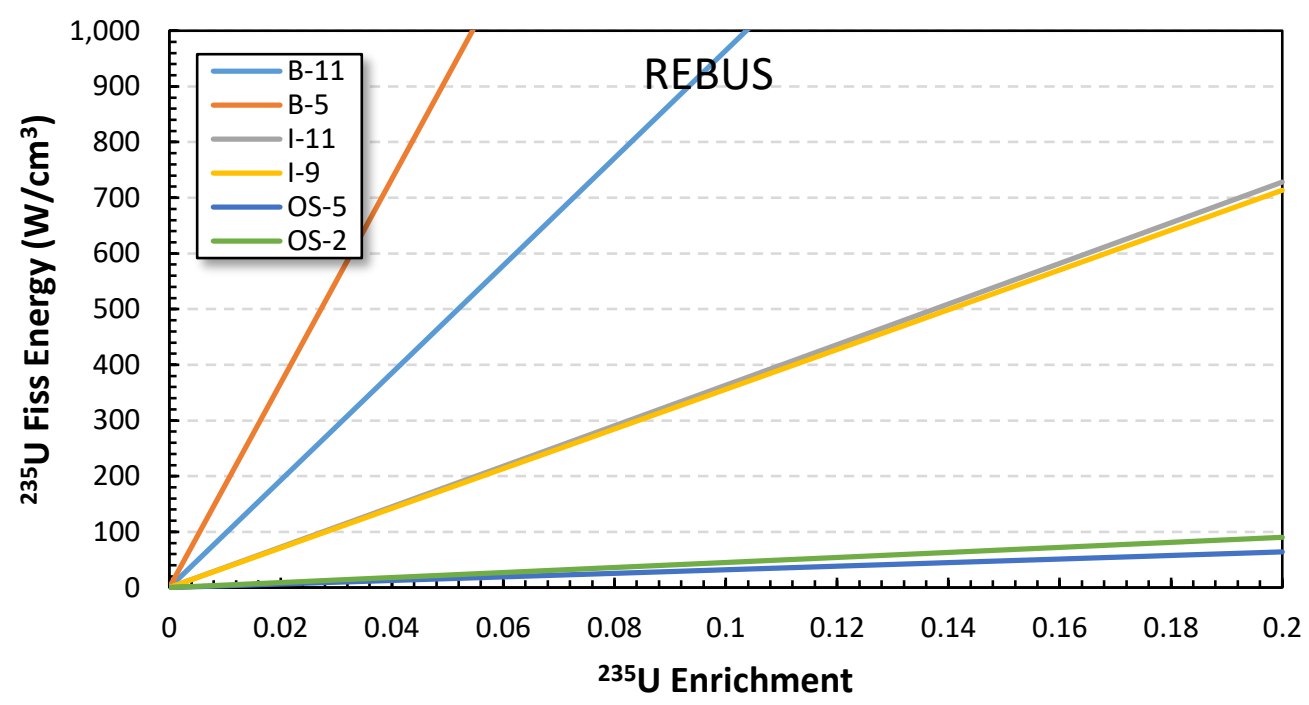

(a) REBUS salt fission energy release versus uranium enrichment.

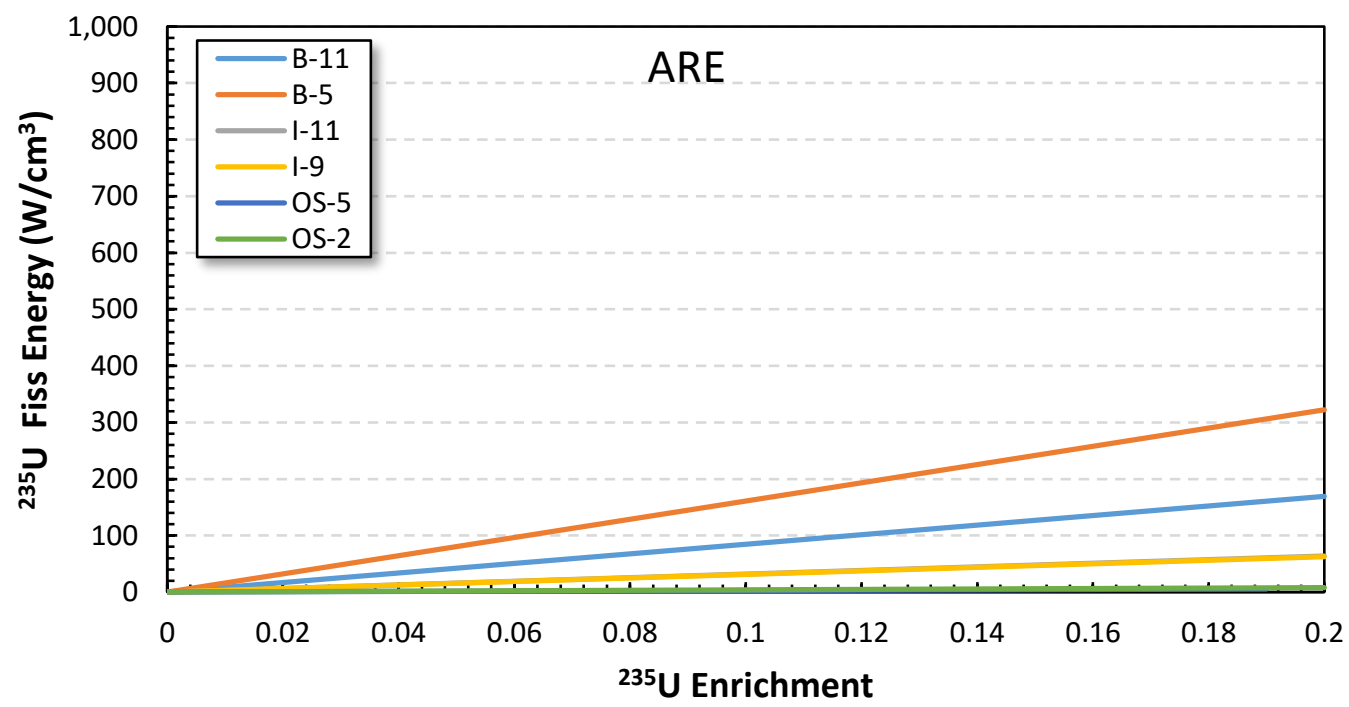

(b) ARE salt fission energy versus enrichment. Note that the different I and O-position curves overlap in the plot. Figure 14. The evolution of ${ }^{235} \mathrm{U}$ fission energy with the salt enrichment in six ATR positions. 
The REBUS and ARE salts were used as showcases to demonstrate the potential power density ranges inside VESIL. The ARE was specifically selected because it is does not contain ${ }^{6} \mathrm{Li}$; therefore, ${ }^{235} \mathrm{U}$ fission is the major (albeit not the only) contributor of heat generation. In order to reach the reactor power density of the REBUS MSR (i.e., $100 \mathrm{~kW} / 1$ [36]), a 1.0\% uranium enrichment is sufficient in the B-11 positions while a $2.8 \%$ enrichment is required for I-11. The O-position would require an enrichment at or above the $20 \%$ limit. In the case of high-actinide content salts intended for fast-spectrum applications, even natural uranium can thus provide useful insight in ATR irradiation.

In addition to uranium enrichment, scoping studies were performed for lithium and chlorine enrichment. Here, ORIGEN calculations were employed to track the production of transmutation products such as ${ }^{3} \mathrm{H},{ }^{35} \mathrm{~S}$, and ${ }^{32} \mathrm{P}$. Figure 15 shows the evolution of tritium production with lithium enrichment for two positions (O-position results are not shown as they remain near the zero line). Depending on the VESIL priorities, a design can opt to maximize tritium production in order to test a control/storage mechanism or can minimize the generation rate in order to avoid having to deal with this challenge.

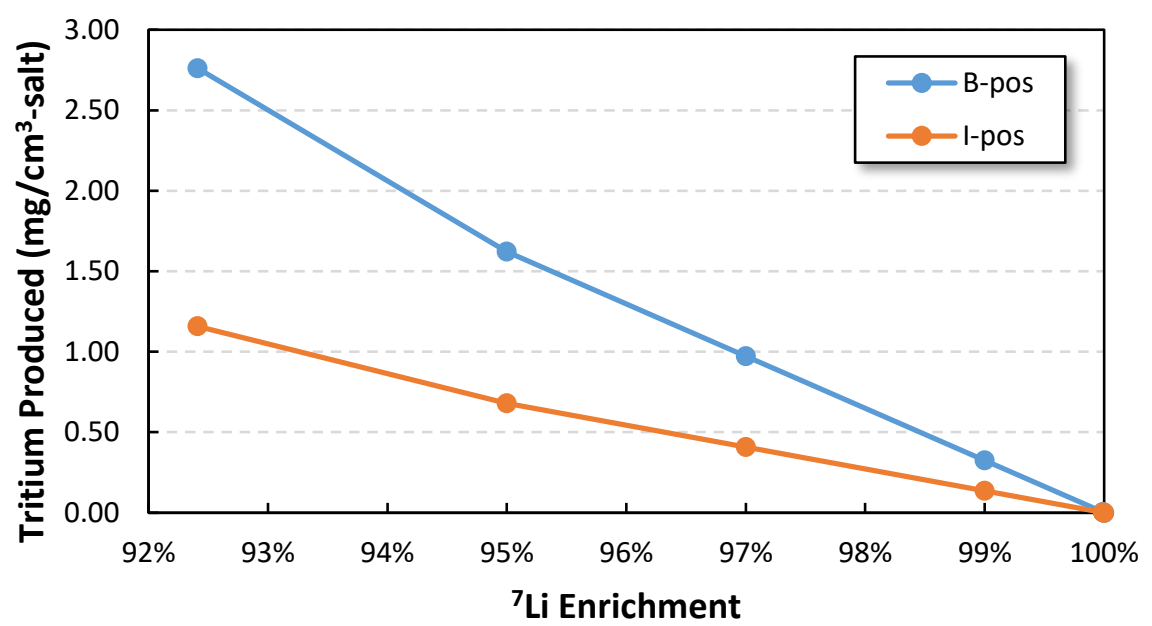

Figure 15. Evolution of tritium production per volume of irradiated FLiBe salt with lithium enrichment.

One of the main transmutation reactions with chloride salts is ${ }^{35} \mathrm{Cl}(\mathrm{n}, \mathrm{p})^{35} \mathrm{~S}$. Sulfur affects the overall salt chemistry; therefore, ${ }^{37} \mathrm{Cl}$ enrichment was also investigated to reduce this impact. Figure 16 plots the variation in sulfur production with the chlorine enrichment in the REBUS salt composition (again, Oposition results are not shown as they remain close to zero). As is the case with tritium, the experiment can be designed to accelerate sulfur production to study its impact on salt chemistry. Alternatively, this effect can be minimized, if needed, by enriching the chlorine. It is worth noting that a large degree of uncertainty currently exists on the chlorine cross-section, especially for the ${ }^{35} \mathrm{Cl}$ isotope absorption crosssection. Efforts are ongoing at institutes such as UC-Berkeley to provide additional experimental data on this [40]. 


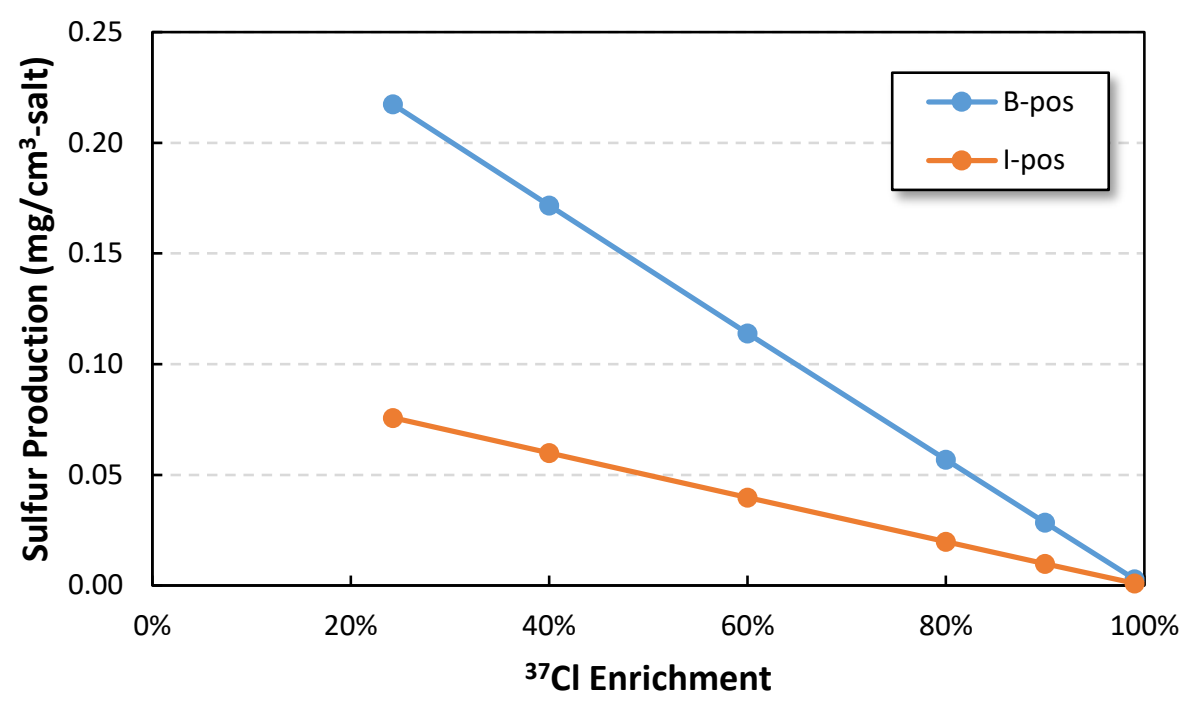

Figure 16. Impact of ${ }^{37} \mathrm{Cl}$ enrichment in REBUS salt on sulfur production from ${ }^{35} \mathrm{Cl}$ transmutation rate.

In addition to modifying enrichment levels, experiments can be tailored by increasing the number of irradiation cycles inside of ATR. A case study was conducted on the MSBR due the availability of opensource information on its equilibrium salt composition [19]. ORIGEN simulations were extended to multiple cycles inside the B, I, and O-positions. A 30-day downtime between cycles was assumed for the ATR, leading to a total time of 90 days between cycle starts. The number of cycles needed to reproduce the equilibrium compositions inside VESIL are summarized in Table 14. The uranium enrichment was $5 \%$ in all cases. The analysis focused on fission products that are soluble and have a long processing time in the MSBR (on the order of days). Variations between different fission products are due to different rates of production and destruction in the ATR spectrum relative to that of the MSBR. It is also attributed to varying processing rates of certain elements (e.g., 30 days for Eu removal versus 16 days for $\mathrm{Ce}$ ). The B-position is able to meet most fission-product thresholds within one cycle while the salt in the I-position needs between two and three cycles to match the various compositions. The O-position on the other hand needs more than a dozen cycles before it can reach some of the targeted compositions. It should be noted that some thresholds (e.g., Sm in the B-position) are reached during downtime, as certain precursor species decay.

Table 14. Number of cycles required to reach the equilibrium MSBR element/isotope concentration in the salt. Linear interpolation was used to determine the number of required cycles. Cycles were assumed to consist of 60 irradiation days and 30 days downtime. The list only contains soluble elements, and the MSBR composition is obtained from ORNL-3579 [19].

\begin{tabular}{|l|c|c|c|c|}
\hline & & \multicolumn{3}{c|}{ Number of cycles required in ATR } \\
\hline Element & MSBR equilibrium & B-position & I-position & O-position \\
\hline $\mathrm{I}$ & $4.57 \times 10^{-6} \mathrm{~g} / \mathrm{cm}^{3}$ & 0.22 cycles & 1.22 cycles & 16.32 cycles \\
\hline $\mathrm{La}$ & $3.50 \times 10^{-5} \mathrm{~g} / \mathrm{cm}^{3}$ & 0.50 cycles & 2.05 cycles & 21.90 cycles \\
\hline $\mathrm{Ce}$ & $9.68 \times 10^{-5} \mathrm{~g} / \mathrm{cm}^{3}$ & 0.49 cycles & 2.04 cycles & 25.81 cycles \\
\hline $\mathrm{Nd}$ & $1.11 \times 10^{-4} \mathrm{~g} / \mathrm{cm}^{3}$ & 0.66 cycles & 2.32 cycles & 22.76 cycles \\
\hline $\mathrm{Pm}$ & $1.19 \times 10^{-5} \mathrm{~g} / \mathrm{cm}^{3}$ & 0.70 cycles & 2.30 cycles & $>30$ cycles \\
\hline $\mathrm{Sm}$ & $1.18 \times 10^{-5} \mathrm{~g} / \mathrm{cm}^{3}$ & 0.57 cycles & 2.17 cycles & 18.89 cycles \\
\hline $\mathrm{Eu}$ & $2.47 \times 10^{-6} \mathrm{~g} / \mathrm{cm}^{3}$ & 1.07 cycles & 3.34 cycles & $>30$ cycles \\
\hline${ }^{233} \mathrm{U}$ & $2.57 \times 10^{-2} \mathrm{~g} / \mathrm{cm}^{3}$ & 4.70 cycles & $>30$ cycles & $>30$ cycles \\
\hline
\end{tabular}


The results showcase an additional tradeoff between the three positions. For the case of the MSBR, it appears unfeasible to match the ${ }^{233} \mathrm{U}$ equilibrium composition in the I or O-position. This is illustrated in Figure 17; the production rate slopes in I-11 and OS-5 are significantly less steep than that of B-11. This is due to a combination of lower flux levels and a much softer spectrum (i.e., the ratio of ${ }^{233} \mathrm{U}$ production over destruction is lower in the I-position). If ${ }^{233} \mathrm{U}$ breeding is considered to be important, a B-position may be required for this type of salt test. It is important to note that these results are strongly affected by the ATR downtime, which is hard to predict and is seldom constant.

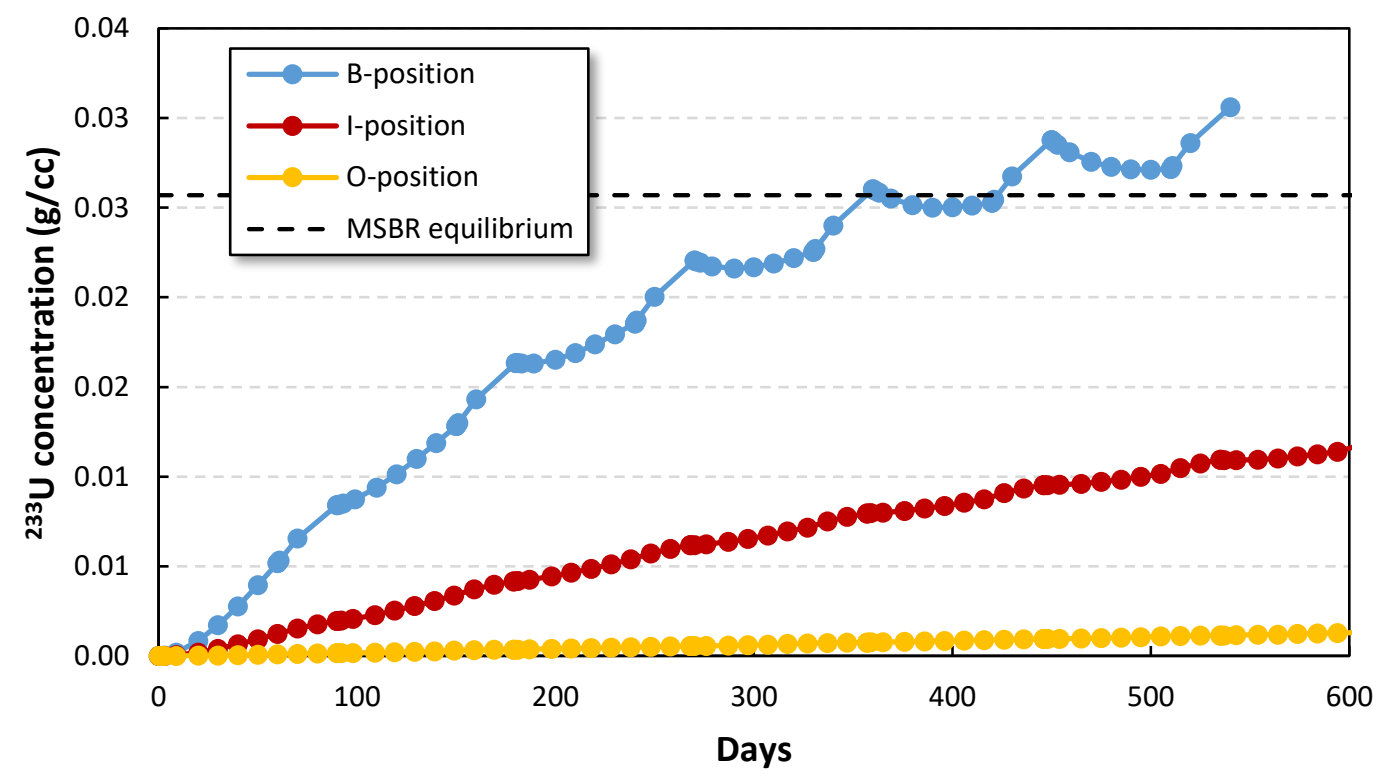

Figure 17. Evolution of the ${ }^{233} \mathrm{U}$ concentration inside the MSBR salt in the B and I-positions. The simulations assumed that all the salt is contained within the active flux region.

\section{SUMMARY AND DISCUSSIONS}

MSRs have attracted significant attention both from private and public enterprises. They offer a range of benefits from a safety, economics, and fuel-utilization perspective. While certain types of salts have been successfully irradiated in the past, little irradiation data is currently available on the specific salts pursued by some vendors. Irradiation testing is therefore crucial to the development of these types of nuclear reactors. Static salt experiments have already been performed at HFR, MITR, and OSURR in recent years. The next stage of irradiation testing would cover the integrated effect of flowing salt velocity with neutron irradiation. Important phenomena like corrosion rates are highly dependent upon both aspects.

This report provides the basis for the design of a molten-salt test loop in the ATR. The test loop is referred to herein as VESIL. Important considerations have been included, including a definition of the experiment scope, an overview of available instrumentation, a review of chemistry control, and a highlevel summary of design decisions. A neutronic feasibility assessment using MCNP6 and ORIGEN 6.2.3 was conducted on a variety of salt candidates. The results indicate that the ATR is a suitable venue for the VESIL test loop and molten-salt experimentation.

This study also finds that the ATR can provide a suitable environment for testing a variety of molten salts. The report identified both the B and I-positions as suitable for VESIL. The O-position are much less desirable in light of the significantly reduced flux in this region. Selecting the experiment position will depend on the candidate salt chosen for irradiation testing. Based on discussions with vendors, it appears that chloride salts are in higher need of testing than their more-established fluoride counterparts. If they are selected for VESIL, the I-position is likely to be a preferred option because lower flux levels 
will be tolerable for a high-uranium-content salt intended for a fast-spectrum reactor. The I-positions also offer larger irradiation volume. The next stage of this project will select a salt candidate and conduct some preliminary design analysis with some safety calculations in order to establish, to a higher degree, the feasibility of VESIL.

\section{ACKNOWLEDGEMENT}

The authors would like to thank Ruchi Gakhar and Guoping Cao for their useful insight on the chemistry and instrumentation of molten salts. The authors are also indebted to Gregory M. Core, who has been instrumental in driving MSR work at INL. Additionally, the authors thank Samuel Bays for his assistance modeling the ATR and for providing example spectrum characteristics. This research work was prepared for the U.S. Department of Energy, through the INL LDRD Program, under DOE Idaho Operations Office. Contract DE-AC07-05ID14517. This research made use of the resources of the HighPerformance Computing Center at Idaho National Laboratory, which is supported by the Office of Nuclear Energy of the U.S. Department of Energy and the Nuclear Science User Facilities under Contract No. DE-AC07-05ID14517.

\section{REFERENCES}

[1] R. E. Thoma, "Chemical Aspects of MSRE Operations," Oak Ridge National Laboratory, ORNL-4658, 1971.

[2] J. McDuffee, N. Cetiner, L. Qualls and K. Thoms, "Evaluation of Flowing Salt Irradiation Facilities with High Neutron Flux," Oak Ridge National Laboratory, ORNL/TM-2018/954, 2018.

[3] W. H. Jordan, S. J. Cramer and A. J. Miller, "Airecraft Nuclear Propulsion Program: Quarterly Progress Report for Period Ending December 31, 1956," Oak Ridge National Laboratory, ORNL-2221, 1957.

[4] D. B. Trauger and J. A. Colin, "Circulating Fused-Salt Fuel Irradiation Test Loop," Nuclear Science and Engineering, vol. 9, pp. 346-356, 1961.

[5] H. C. Savage, E. Campere, J. M. Baker and E. G. Bohlmann, "Operation of Molten-Salt Convection Loops in the ORR," Oak Ridge Naitonal Laboratory, 1960.

[6] J. A. Conlin, "MSPR In-Pile Loop ORNL-MTR-44 Design and Operating Conditions," Oak Ridge National Laboratory, ORNL-58-10-64, 1958.

[7] P. R. Hania, "MSR Irradiation Program at NRG Petten," in MSR Workshop 2018, Oak Ridge, 2018.

[8] C. W. Forsberg, P. F. Peterson, K. Sridharan, L. Hu, M. Fratoni and A. Kant-Prinja, "Integrated FHR Technology Development: Trititum Management, Materials Testing, Salt Chemistry Control, Thermal Hydraulics and Neutronics, Associated Benchmarking and Commercial Basis," NEUP Report, MIT-ANP-TR$180,2018$.

[9] J. J. Powers, N. R. Brown, D. E. Mueller, B. W. Patton, E. Losa and M. Kostal, "Sensitivity/uncertainty analyses comparing LR-0 reactor experiments containing FLiBe salt with models for molten-salt-cooled and molten-salt-fueled reactors," Annals of Nuclear Energy, vol. 120, pp. 319-332, 2018.

[10] N. D. Ezell, J. McDuffee, K. Smith and S. Raiman, "Initial Irradiation Testing of Chloride Salts for Molten Salt Reactors," in ANS Winter Meeting, Orlando, 2018.

[11] U.S. Nuclear Regulatory Commission, "NUREG-800 Chapter 15.0.2," 2007.

[12] Terrapower, "Terrapower's Molten Chloride Fast Reactor Program," in ANS Utility Conference, Amelia Island, 2017.

[13] D. E. Holcomb, R. A. Kisner and S. M. Cetiner, "Instrumentation Framework for Molten Salt Reactors," Oak Ridge National Laboratory, ORNL/TM-2018/868, 2018.

[14] P. Calderoni and C. Jensen, "In-Pile Instrumentation Strategic Plan," Idaho National Laboratory, INL/EXT18-51432, 2018.

[15] J. Daw, P. Calderoni, J. Smith, A. Fleming, N. Kandadai, H. Subbaraman and L. Li, "Radiation Tolerant Optical Fibers and Sensors: FY 2018 Report," Idaho National Laboratory, INL/EXT-18-51463, 2018.

[16] K. L. Davis, D. L. Knudson, J. L. Rempe, J. C. Crepeau and S. Solstad, "Design and Laboratory Evaluation of Future Elongation and Diameter Measurements at the Advanced Test Reactor," Nuclear Technology, vol. 191, no. 1, pp. 92-105, 2015. 
[17] D. M. Scates, J. K. Hartwell, J. B. Walter, M. W. Drigert and J. M. Harp, "Fission Product Monitoring of TRISO Coated Fuel for the Advanced Gas Reactor-1 Experiment," Idaho National Laboratory, INL/CON-0814135, 2008.

[18] W. R. Grimes, "Molten-Salt Reactor Chemistry," Nuclear Applications \& Technology, vol. 8, no. 2, pp. 137$155,1970$.

[19] W. L. Carter and E. L. Nicholson, "Design and Cost Study of a Fulorination - Reductive Extraction - Metal Transfer Processing Plant for the MSBR," Oak Ridge National Laboratory, ORNL-TM-3579, 1972.

[20] J. Zhanga, C. W. Forsberg, M. F. Simpson, S. Guo, S. T. Lamb, R. O. Scarlat, F. Carotti, K. J. Chan, P. M. Singh, W. Doniger, K. Sridharan and J. R. Keiser, "Redox potential control in molten salt systems for corrosion mitigation," Corrosion Science, vol. 144, pp. 44-53, 2018.

[21] D. J. Oakley, "Closed Loop In-Reactor Assembly (CLIRA) a Fast Flux Test Facility Vehicle," in ASME Winter Annual Meeting, San Fransisco, 1978.

[22] V. N. Efimov, I. Y. Zhemkov, A. N. Kozolup, V. I. Polyakov, V. T. Stepanov, Y. E. Stynda, V. V. Orlov, A. I. Filin, A. Sila-Novitsky and A. A. Pikalov, "The BOR-60 Loop-Channel Design for Testing the BREST Reactor Fuel," International Atomic Energy Agency, IAEA-TECDOC-1348, 2003.

[23] D. Gerstner and C. Davis, "Thermal-Hydraulic Analysis Results of a Seismically-Induced Loss of Coolant Accident Involving Experiment Out-of-Pile Loop Piping at the Idaho National Laboratory Advanced Test Reactor," in EFCOG 2012 Safety Analysis Workshop, Santa Fe, 2012.

[24] V. N. Leonov, A. I. Filin, V. N. Yefimov, A. D. Yurchenko and Y. U. Shtynda, "Pre and In-Pile Tests of Fuel Element Mock-Ups for the BREST-OD-300 in the Independent Lead-Cooled Channel of the BOR60 Reactor," in 11th International Conference on Nuclear Engineering, Tokyo, 2003.

[25] J. McDuffee, D. Felde and J. Carbajo, "Design and Testing for a New Thermosyphon Irradiation Vehicle," Oak Ridge National Laboratory, ORNL/TM-2017/399, 2017.

[26] S. B. Grover and D. A. Petti, "Design and Status of the NGNP Fuel Experiment AGR-3/4," in Proceedings of the HTR, Tokyo, Japan, 2012.

[27] Idaho National Laboratory, "FY 2009 Advanced Test Reactor National Scienctific User Facility Users' Guide," ATR National Scientific User Facility, INL/EXT-08-14709, 2009.

[28] S. S. Kim and B. G. Schnitzler, "Advanced Test Reactor: Serpentine Arrangement of Highly Enriched WaterModerated Uranium-Aluminide Fuel Plates Reflected by Beryllium," Idaho National Laboratory, HEU-METTHERM-022, 2005.

[29] B. T. Rearden and M. A. Jessee, "Scale Code System Version 6.2.3," Oak Ridge National Laboratory, ORNL/TM-2005/39, 2018.

[30] A. Qualls, N. Brown, B. Betzler, J. Carbajo, M. Greenwood, R. Hale, T. Harrison, J. Powers, K. Robb, J. Terrell and A. Wysocki, "Fluoride Salt-Cooled High-Temperature Demonstration Reactor Point Design," Oak Ridge National Laboratory, ORNL/TM-2016/85, 2016.

[31] W. B. Cottrell, H. H. E., J. K. Leslie and J. L. Meem, "Operation of the Aircraft Reactor Experiment," Oak Ridge National Laboratory, ORNL-1845, 1955.

[32] J. H. Shaffer, "Preparation and Handling of Salt Mixtures for the Molten Salt Reactor Experiment," Oak Ridge National Laboratory, ORNL-4616, 1971.

[33] R. C. Robertson, "Conceptual Design Study of a Single-Fluid Molten-Salt Breeder Reactor," Oak Ridge National Laboratory, ORNL-4541, 1971.

[34] A. Sowder, "Program on Technology Innovation: Technology Assessment of a Molten Salt Reactor Design," Electric Power Research Institute, 3002005460, 2015.

[35] Transatomic Power, "Technical White Paper November 2016 v2.1," 2016.

[36] A. Mourogov and P. M. Bokov, "Potentialities of the fast spectrum molten salt reactor concept: REBUS3700," Energy Conversion and Management, vol. 47, pp. 2761-2771, 2006.

[37] G. J. Janz, A. T. Ward and R. D. Reevers, "Molten Salt Data: Electrical Conductance, Density, and Viscosity," Rensselaer Polytechnic Institute, Troy, N. Y., 1964.

[38] V. N. Desyatnik, S. F. Katyshev, S. P. Raspopin and Y. F. Chervinskii, "Density, Surface Tension, and Viscosity of Uranium Trichloride-Sodium Chloride Melts," Atommaya Energiya, vol. 39, no. 1, pp. 70-72, 1975. 
[39] M. Aufiero, A. Cammi, C. Fiorina, J. Leppanen, L. Luzzi and M. E. Ricotti, "An extended version of the SERPENT-2 code to investigate fuel burnu-up and core material evolution of the Molten Salt Fast Reactor," Journal of Nuclear Materials, vol. 441, pp. 473-486, 2013.

[40] J. C. Batchelder, S. A. Chong, M. A. Unzueta and M. Fratoni, "Measurement of the $35 \mathrm{Cl}(\mathrm{n}, \mathrm{p})$ and $35 \mathrm{Cl}(\mathrm{n}, \mathrm{a})$ Cross-Sections at the Berkeley High Flux Neutron Generator," in Transactions of the American Nuclear Society, vol. 117, Washington D.C., 2017.

[41] S. S. Kim and B. G. Schnitzler, "Advanced Test Reactor: Serpentine Arrangement of Highly Enriched WaterModerated Uranium-Aluminide Fuel Plates Reflected by Beryllium," Idaho National Laboratory, 2010.

[42] D. Carpenter, M. Ames, G. Zheng, G. Kohse and L. Hu, "Tritium Production and Partitioning from the Irradation of Lithium-Beryllium Fluoride Salt," Fusion Science and Technology, vol. 71, pp. 549-554, 2017. 


\section{Appendix A}

\section{VESIL Preliminary Cost Estimate}

The main historical basis for the cost estimates of VESIL was the AGR experiments [26]. An internal review was conducted at INL with a summary of costs provided in Table 15. It should be noted that several of the later phases of AGR are still undergoing irradiation or PIE, and their corresponding estimates are currently incomplete. They are therefore not provided. Only AGR-1 has been fully completed. The higher cost of AGR-1 relative to AGR-2 is mostly due to its first-of-kind nature, with subsequent experiments leveraging a lot of the existing infrastructure and learning experience. AGR-5/6/7 also saw a significant cost increase because it included the industrial-scale fuel fabrication that was conducted for these tests (TRISO fuel fabrication was subcontracted to a private industrial partner) alongside the experiment fabrication.

Table 15. ATR Experiment cost by phase and constituent. ${ }^{2}$

\begin{tabular}{|l|c|c|c|c|c|}
\hline Experiment & Design & Fabrication & Irradiation & PIE & Total \\
\hline AGR-1 & $\$ 1,443,597$ & $\$ 11,537,321$ & $\$ 12,880,700$ & $\$ 44,772,307$ & $\mathbf{\$ 7 0 , 6 3 3 , 9 2 5}$ \\
\hline AGR-2 & $\$ 959,195$ & $\$ 11,639,762$ & $\$ 9,187,786$ & - & $\mathbf{\$ 2 1 , 7 8 6 , 7 4 3}$ \\
\hline AGR-3/4 & $\$ 2,936,066$ & $\$ 3,830,259$ & $\$ 14,506,072$ & - & $\mathbf{\$ 2 1 , 2 7 2 , 3 9 7}$ \\
\hline AGR-5/6/7 & $\$ 3,626,713$ & $\$ 42,092,170$ & - & - & $\mathbf{\$ 4 5 , 7 1 8 , 8 8 3}$ \\
\hline
\end{tabular}

The experiment costs in Table 15 were used alongside expert guidance to provide a baseline cost estimate for the VESIL experiment in Table 16. Costs for alternate versions of the experiment with larger scope will build on this base estimate. The values derived for VESIL do not quantify potential uncertainties and are only first order estimates. The VESIL base cost corresponds to the lower bound of the scope in the cheapest version of the experiment, i.e. Design A. The estimates assume that only measurement tools and components requiring limited R\&D are selected, and the majority of available INL infrastructure can be leveraged. The minimum design and fabrication costs are expected to be similar to those of AGR-1, albeit slightly higher to account for the difficulty in handling molten salt and the additional prototyping required to test the flow circulation. The design and fabrication estimates would include prototyping, out-of-pile testing, as well as installation inside of ATR. They do not account for the cost of salt fabrication since this will be strongly dependent on the MSR concept (a major driver in the AGR costs). However, the reductions in fuel fabrication are expected to be more than compensated for by the additional testing and prototyping in this phase. As such, a base cost for the design and fabrication stage of $\$ 15 \mathrm{M}$ was estimated. The irradiation cost is likely to be very similar to the range observed in AGR $(\$ 10-\$ 15 \mathrm{M})$. The lower bound of $\$ 10 \mathrm{M}$ was assumed for the baseline Design A cost. Irradiation costs are mainly driven by labor, this includes hiring: experiment operators, experiment engineers, as-run physics modeling scientists, and project managers. The irradiation phase also includes the cost of setting up a fission gas monitoring system in addition to the general ATR irradiation costs (fees for all experiments in the reactor). The baseline PIE cost for VESIL is assumed to be much lower than that of AGR-1 if no new facilities are needed. The base version would only rely on existing facilities at the Materials and Fuel Complex (MFC) at INL, such as furnaces and thermal property measurement equipment. Nevertheless, a base value of $\$ 10 \mathrm{M}$ was deemed necessary to hire staff to conduct the PIE and setup the required measurements within these existing facilities. As a result, the total base cost of VESIL is estimated at $\$ 35 \mathrm{M}(15+10+10)$.

In the case of Design A (natural convection), additional costs can be incurred if the scope of the experiment is expanded. The design phase will likely require several prototypes and extensive out-of-pile

\footnotetext{
${ }^{2}$ Obtained from internal INL accounting.
} 
testing. The scope could be extended to include less proven in-situ measurement tools (e.g. fiber optics) or a complex chemistry control mechanism. As such, an additional expenditure of $\$ 5 \mathrm{M}$ is envisaged for this phase. The upper bound of the AGR irradiation cost could also be assumed for the Design A variant with a larger scope (additional $\$ 5 \mathrm{M}$ ). If new facilities are needed for PIE, it can cost around $\$ 5 \mathrm{M}$ for each new equipment setup (e.g. ultrasonic or optical). In the case that two new custom-made facilities are required and the amount of staff required to investigate the larger scope items increases by $50 \%$, an added $\$ 15 \mathrm{M}$ would have to be allocated for PIE. Overall, the larger scope variant for Design A is expected to add $\$ 25 \mathrm{M}(5+5+15)$ to the base estimate.

The baseline cost of Design B (forced convection), are similar to those of Design A with the exception of the initial design, mockup, and fabrication phase. Here, substantial R\&D is likely needed to develop and test components such as pumps, valves, and motors. These systems will need to survive both the flowing salt and the irradiation environment. This development campaign was estimated to add at least another $\$ 15 \mathrm{M}$ to the base costs of Design A. If the scope is expanded further, an additional $\$ 10 \mathrm{M}$ would be needed for $\mathrm{R} \& \mathrm{D}$ on less conventional components and new measurement capabilities. The irradiation costs of the base and larger scope variant of Design B are similar to those in Design A.

Baseline PIE costs are the same as Design A. The larger scope version of Design B is assumed to have the same PIE costs as those quoted in AGR-1. Table 16 provides a summary of the cost breakdown for the two experiments. As previously stated, these estimates are very approximate and do not account for associated uncertainty ranges.

Table 16. Breakdown of cost estimates for VESIL. Note that values are very preliminary, and no attempt was made to quantify the uncertainties associated with these values.

\begin{tabular}{|l|c|c|c|c|}
\cline { 2 - 5 } \multicolumn{1}{c|}{} & \multicolumn{2}{c|}{ Design A } & \multicolumn{2}{c|}{ Design B } \\
\cline { 2 - 5 } \multicolumn{1}{c|}{} & Base Cost & Larger Scope & Base Cost & Larger Scope \\
\hline Design, Mockup, and Fabrication & $\$ 15 \mathrm{M}$ & $\$ 20 \mathrm{M}$ & $\$ 30 \mathrm{M}$ & $\$ 40 \mathrm{M}$ \\
\hline Irradiation and Monitoring & $\$ 10 \mathrm{M}$ & $\$ 15 \mathrm{M}$ & $\$ 10 \mathrm{M}$ & $\$ 15 \mathrm{M}$ \\
\hline Post-Irradiation Examination & $\$ 10 \mathrm{M}$ & $\$ 25 \mathrm{M}$ & $\$ 10 \mathrm{M}$ & $\$ 45 \mathrm{M}$ \\
\hline Total & $\mathbf{\$ 3 5 M}$ & $\mathbf{\$ 6 0 M}$ & $\mathbf{\$ 5 0 M}$ & $\mathbf{\$ 1 0 0 M}$ \\
\hline
\end{tabular}




\section{Appendix B}

\section{VESIL Irradiation Tables}

Results from the ORIGEN analysis are summarized in Table 17.

Table 17. Density (in $\mathrm{g} / \mathrm{cm}^{3}$-salt) of isotopes/elements after 1 cycle irradiation in the ATR (60 days).

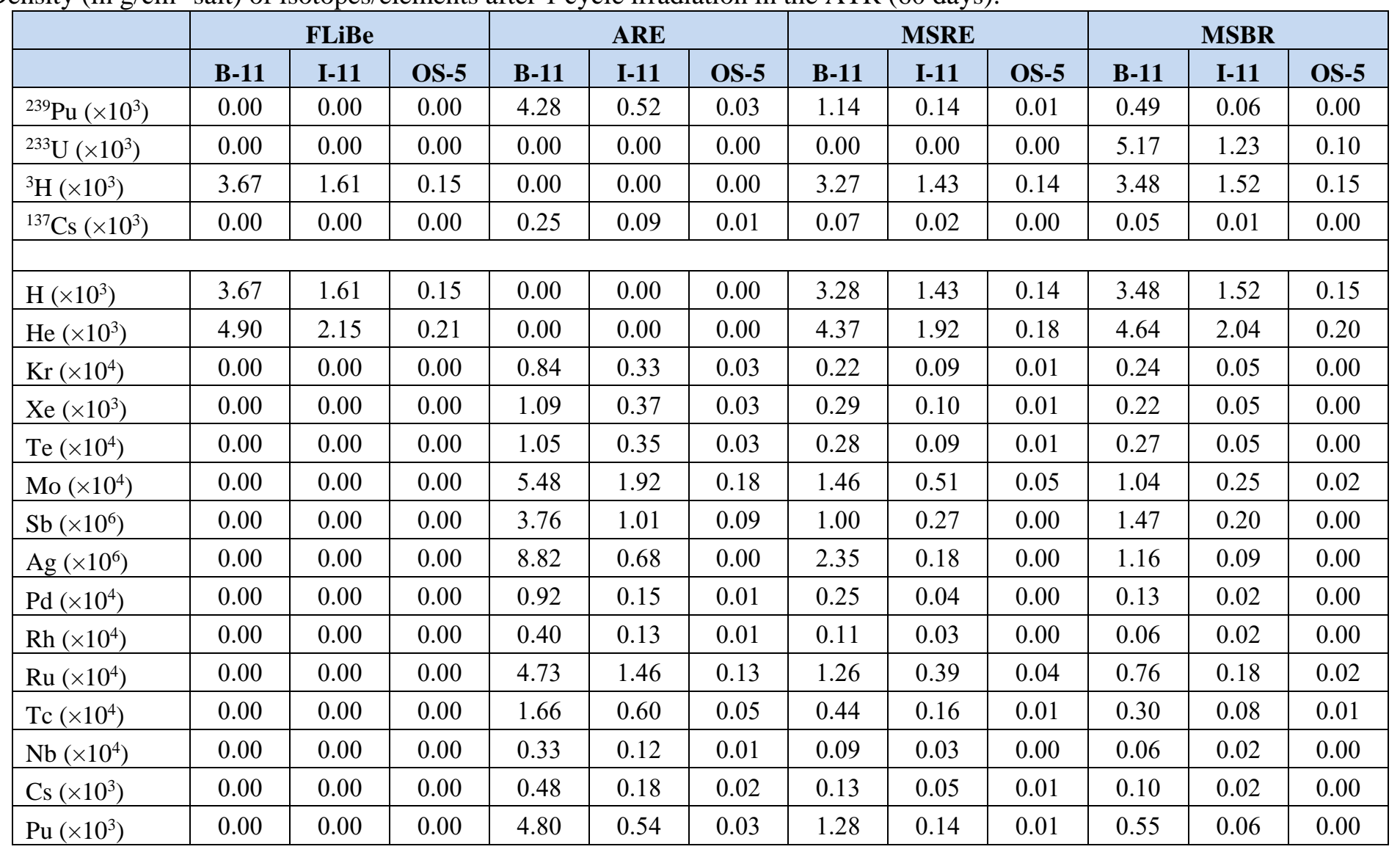




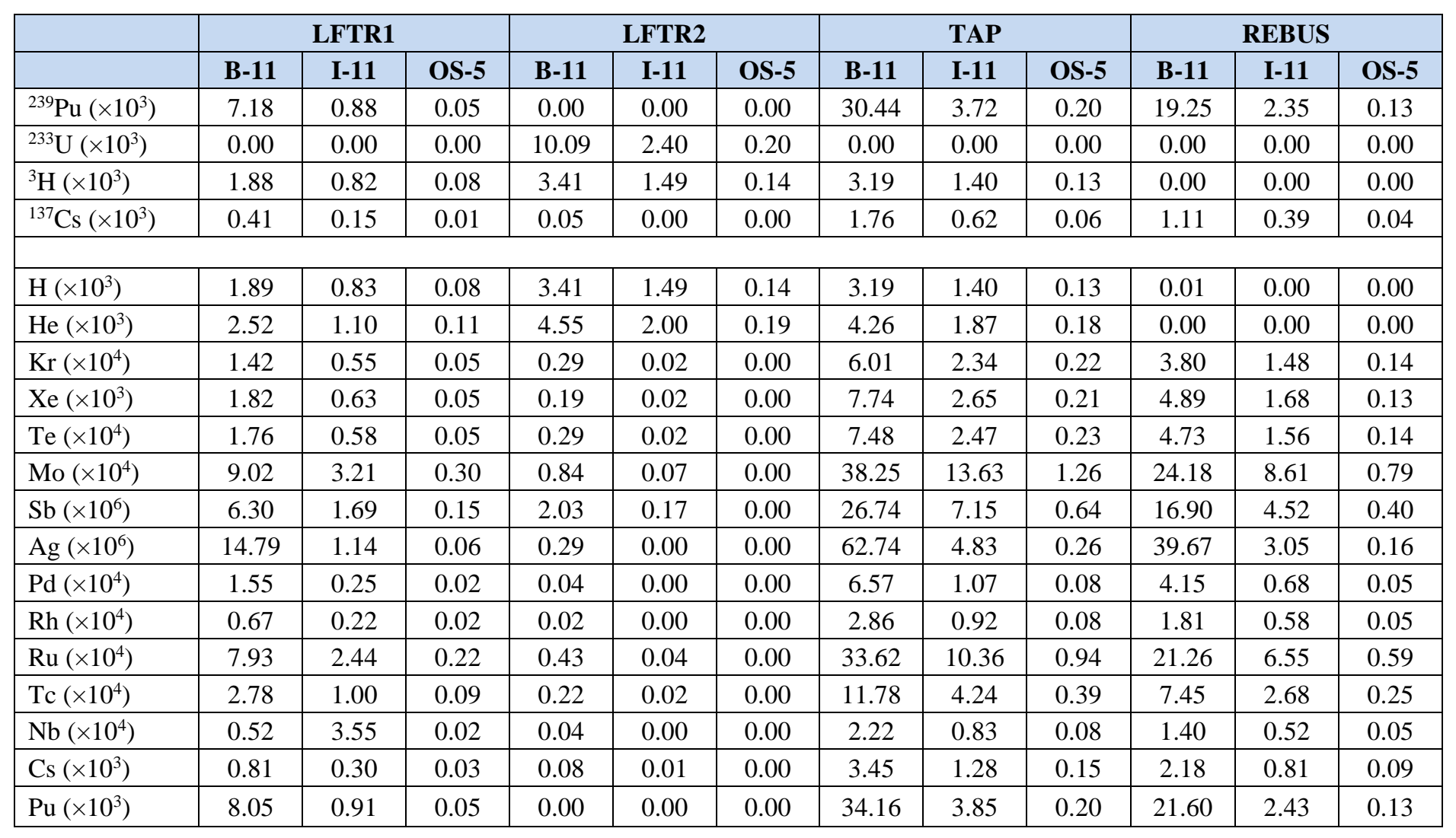

